\title{
Genomic Insights into the Demographic History of Southern Chinese
}

\author{
Xiufeng Huang ${ }^{1, \#}$, Zi-Yang Xia ${ }^{2,3,4, \# *}$, Xiaoyun Bin ${ }^{1, \#}$, Guanglin $\mathrm{He}^{2}$, Jianxin Guo ${ }^{2}$,
} Chaowen Lin ${ }^{1}$, Lianfei Yin ${ }^{1}$, Jing Zhao ${ }^{2}$, Zhuofei $\mathrm{Ma}^{1}$, Fuwei $\mathrm{Ma}^{1}$, Yingxiang $\mathrm{Li}^{2}$, Rong $\mathrm{Hu}^{2}$, Lan-Hai $\mathrm{Wei}^{2}$, Chuan-Chao Wang ${ }^{2, *}$

1. College of Basic Medical Sciences, Youjiang Medical University for Nationalities, Baise, Guangxi 533000, China

2. Department of Anthropology and Ethnology, Institute of Anthropology, School of Sociology and Anthropology, and National Institute for Data Science in Health and Medicine, School of Life Sciences, Xiamen University, Xiamen 361005, China 3. Division of Biosciences, University College London, London WC1E 6BT, United Kingdom

4. Ministry of Education Key Laboratory of Contemporary Anthropology, Department of Anthropology and Human Genetics, School of Life Sciences, Fudan University,

Shanghai 200438, China

\# These authors contributed equally to this work.

* Corresponding author: Professor Chuan-Chao Wang (wang@xmu.edu.cn) and Zi-Yang Xia (ziyang.xia.20@ucl.ac.uk).

\section{ABSTRACT}

Southern China is the birthplace of rice-cultivating agriculture, different language families, and human migrations that facilitated these cultural diffusions. The fine-scale demographic history in situ, however, remains unclear. To comprehensively cover the genetic diversity in East and Southeast Asia, we generated genome-wide SNP data from 211 present-day Southern Chinese and co-analyzed them with more than 1,200 ancient and modern genomes. We discover that the previously described 'Southern East Asian' or 'Yangtze River Farmer' lineage is monophyletic but not homogeneous, comprising four regionally differentiated sub-ancestries. These ancestries are respectively responsible for the transmission of Austronesian, Kra-Dai, Hmong-Mien, and Austroasiatic languages and their original homelands successively distributed from East to West in Southern China. Multiple phylogenetic analyses support that the earliest living branching among East Asian-related populations is First Americans ( 27,700 BP), followed by the pre-LGM differentiation between Northern and Southern East Asians ( 23,400 BP) and the pre-Neolithic split between Coastal and Inland Southern East Asians ( 16,400 BP). In North China, distinct coastal and inland routes of south-to-north gene flow had established by the Holocene, and further migration and admixture formed the genetic profile of Sinitic speakers by $\sim 4,000$ BP. Four subsequent massive migrations finalized the complete genetic structure of present-day Southern Chinese. First, a southward 
Sinitic migration and the admixture with Kra-Dai speakers formed the 'Sinitic Cline'. Second, a bi-directional admixture between Hmong-Mien and Kra-Dai speakers gave rise to the 'Hmong-Mien Cline' in the interior of South China between $\sim 2,000$ and $\sim 1,000$ BP. Third, a southwestward migration of Kra-Dai speakers in recent $\sim 2,000$ years impacted the genetic profile for the majority of Mainland Southeast Asians. Finally, an admixture between Tibeto-Burman incomers and indigenous Austroasiatic speakers formed the Tibeto-Burman speakers in Southeast Asia by 2,000 BP.

\section{INTRODUCTION}

Dated to $\sim 9,000$ years before present (BP), Southern China is one of the two earliest agricultural centers in East Asia ${ }^{1,2}$. The First Farmers in Southern China domesticated a series of plants and animals indispensable for present-day people ${ }^{3}$, among which the most famous one is wet rice (Oryza japonica) ${ }^{4}$. It has long been hypothesized that the farming dispersal from Southern China involves human migration and in term the language families spoken by the farmers ${ }^{5}$. Recent studies have shown that the First Farmers in Southeast Asia ${ }^{6,7}$ and Pacific Islands ${ }^{8-10}$ derived most of their ancestry from a lineage shared with modern Southern Chinese, which has further been confirmed by ancient genomes from Fujian in coastal Southern China ${ }^{11}$ and adjacent Taiwan Island ${ }^{12}$. These finding supports the involvement of massive migration in the diffusion of Austronesian and Austroasiatic languages. However, our knowledge is still limited about the deep origin and early prehistory of such a 'Southern East Asian' or 'Yangtze River Farmer' lineage and its role in the genomic formation of modern Southern Chinese, especially the speakers of the other two indigenous language families in Southern East Asia, Hmong-Mien and Kra-Dai.

Here we generated new genome-wide data of 211 present-day Southern Chinese individuals, who belong to 30 geographic subgroups that have not yet been represented in genomic studies and cover the three main language families in this region, i.e., Hmong-Mien, Kra-Dai, and Sino-Tibetan. To thoroughly reconstruct the demographic history of Southern Chinese in relation to other East Asians, we co-analyzed them with 1,200 modern and high-coverage ancient samples from East and Southeast Asia, which cover the main ethnolinguistic and archaeological diversity in East Asia that is accessible till now with a high resolution.

Our study mainly addressed on three primary questions regarding the genomic history in East Asia. (1) How many ancestries substantially contributed to the gene pool of present-day East Asians and to what extent did they participate in the diffusion of different language families? Especially, if there are any sub-structure with the Southern East Asians? (2) What is the deep history regarding the origin of these ancestries and where did they originally inhabit? (3) What migrations and admixtures did these ancestries involve in the formation of present-day Southern Chinese? 
In response to questions above, we first gained an overview of genetic structure by principal component analysis (PCA) ${ }^{13}$ (Fig. 1A and B) and model-based clustering ${ }^{14}$ (Fig. 1C). To quantify the genetic affinity, we measured the degree of shared genetic drift $^{15}$ (Fig. 2A) and shared haplotypes ${ }^{16}$ (Fig. 2B and C) among pairwise populations. We performed admixture graph modelling (Fig. 3A), admixture proportion estimation (Fig. 3B), and coalescent analysis based on site frequency spectrum (SFS) (Fig. 3C) to investigate the deep phylogenetic relationship and infer the geographic distribution of these ancestries. We then applied multiple methods, including the formal test of genetic homogeneity (Fig. 4), to further explore the admixtures in Southern China. Demographic history in East Asia and recent migrations and admixtures in Southern China has been summarized into map illustrations (Fig. 5). All the analyses above allow us to better decipher both the long-term prehistory and recent two millennia's documented history along with Sinicization in Southern China from a genomic perspective.

\section{RESULTS}

\section{A. Genetic structure in East Asia highly corresponds to linguistic affiliations}

PCA of all the ancient and modern East Asians in our dataset (Fig. 1A) replicates the pattern of genetic differentiation between Northern and Southern East Asians ${ }^{11,12}$ and variations between two geographically structured clusters within Northern East Asia $^{12,17}$. The 'Inland Yellow River Cluster' is best represented by Neolithic Farmers from Inland Yellow River Basin (Yangshao_MN and Qijia_LN ${ }^{17}$ ) and later and modern Tibetan Plateau inhabitants. In ADMIXTURE plot (Fig. 1C), the ancestry maximizing in this cluster is also ubiquitous in modern Sino-Tibetan speakers (Fig. 1C), consistent with previous linguistic studies that suggested a plausible origin of Proto-Sino-Tibetan in Yangshao Culture ${ }^{18,19}$. The 'Northeast Asian Cluster' is typified by the Neolithic hunter-gatherers in Amur River Basin (DevilsCave_N ${ }^{18,19}$ and Boisman_MN ${ }^{12}$ ), Mongolian Plateau, and Cis-Baikal (Shamanka_EN and Lokomotiv_EN ${ }^{19}$ ), as well as modern populations from Amur River region (Fig. 1A), and these surrogates also harbor the highest proportion of the ancestry prevalent in modern Tungusic speakers and other Northeast Asians. We observe consistent clustering manners in pairwise outgroup- $f_{3}$ (Fig. 2A) and haplotype sharing degree measured by identity-by-descent (IBD) chunks (Fig. 2B and C).

Confirming the highly shared genetic history among the Southern East Asians, we find that Kra-Dai and Hmong-Mien populations in Southern China, Southern Han Chinese, and Austronesian Taiwanese cluster together with a high sharing degree $\left(f_{3}>\right.$ 0.320 ) in outgroup- $f_{3}$ matrix (Fig. 2A). We further identify a previously unknown genetic structure within the Southern East Asians that has a strong connection with linguistic classification. That is, each of the speakers of all the four indigenous 
language families in Southern China and Southeast Asia has their own cluster in PCA for Southern East Asians (Fig. 1B) and their own ancestral component in

ADMIXTURE plot (Fig. 1C). Austronesian-related ancestry maximizes in ancient and modern Austronesian Taiwanese with a high proportion in earlier Fujian Neolithic individuals. Austroasiatic-related ancestry maximizes in Neolithic farmers in Mekong River Basin (collectively referred as 'Mekong_N' afterwards) and is also extensively distributed in Mainland Southeast Asia. Hmong-Mien-related ancestry maximizes in the Western Hmong populations (Miao_Longlin and Miao_Xilin) newly reported in this study and is absent in all the ancient individuals, indicating that the original homeland of this ancestry has not yet been sampled in ancient genomic studies to date. Kra-Dai-related ancestry maximizes in modern Kra-Dai speakers resident in Mainland Southern China (Zhuang, Maonan, Mulam) and neighboring Hainan Island (Hlai). Especially in Austronesian- and Hmong-Mien-speaking populations, we observe a high degree of IBD sharing between the surrogate populations with other populations of the same language affiliation [number $>11.5$, length $>18.5 \mathrm{cM}$ for Atayal; number $>$ 12.4 , length $>32.0 \mathrm{cM}$ for Miao_Longlin], which indicates strong genetic drift or founder effect in both ancestries. We use the terms 'Core Austronesians/ Kra-Dais/ Hmong-Miens/ Austroasiatics' to address modern surrogates of each of the ancestries.

We implemented point-biserial correlation to formally examine if the proportion of ancestries in ADMIXTURE is significantly associated with corresponding language families (Extended Data Table 2), which shows a strong correlation to linguistic affiliation for all the six major ancestries in East Asia $\left(\mathrm{r}_{\mathrm{pb}}>0.500, p<0.0001\right)$. The gene-language correlation indicates that present-day speakers of the major language families in East Asia usually receive a strong genomic legacy from the speakers of corresponding proto-languages, which enables us to trace the history of these language families through the history of human populations.

\section{B. Reconstruction of ancestral homelands in Southern China}

One of the crucial historical aspects for a language family is its original homeland, or Urheimat. In historical linguistics, two main strategies have been applied for the reconstruction of linguistic homeland ${ }^{20}$. One of the strategies leverages the reconstructed vocabulary of the proto-language to inform us about the environment and lifestyle of the original speakers, which is in turn a clue for geographic origin. The other strategy assumes that the linguistic homeland tends to be located in where there is a higher linguistic diversity ${ }^{21}$.

However, both linguistic strategies cannot work well in case of the four major language families that are indigenous in Southern East Asia and are supposed to originate from Southern China. First, all of the four language families share some words reflecting either a common origin or extensive language contact among all of them, especially the ones related to farming and domestication ${ }^{22}$, which prevents us to infer the homeland distribution within Southern China in a higher resolution. Second, 
massive cultural transition happened in Southern China in recent millennia, especially Sinicization $^{23}$, may have largely decreased language diversity in this region. Given the language-associated genomic structure in Southern East Asia, here we adapted another genomics-based strategy - modelling the phylogenetic relationship among the ancestries to infer their relative geographic distribution, hence the homelands for the language families they spread.

We implemented $q p G r a p h^{24}$ to model the phylogenetic relationship of the main ancestries in East Asia, using populations in which the corresponding ancestries maximize in PCA (Fig. 1A and B) and ADMIXTURE (Fig. 1C) as surrogates. Our optimal model (Fig. 3A) shows that Northern East Asians (Mongolia_N, Boisman_MN, and Sherpa) and Southern East Asians (Hanben_IA, Hlai_Qiongzhong, Miao_Longlin, and MSEA_N) each form a monophyletic lineage, with additional admixture from an Andamanese-related deep ancestry in the common ancestor of Southern East Asians (31\%). As Core Kra-Dais, Core Hmong-Miens, and the earliest Austronesian-related ancient group (Qihe_EN and Liangdao_EN) are located in Southern China, we can reasonably deduct that the common ancestor of Southern East Asian lineage and its initial diversification also took place in Southern China.

Sub-topology within the Southern East Asian lineage suggests that Austronesian ancestry split with the others first, then followed by Kra-Dai ancestry, with Hmong-Mien and Austroasiatic ancestries sharing the most genetic drift with each other. Given the easternmost and westernmost geographic position respectively for the earliest Austronesian- (Qihe_EN and Liangdao_EN) and Austroasiatic-related (Mekong_N) individuals, such a topology can be explain as a result of the isolation-by-distance pattern from east to west in ancient Southern China sequentially for Austronesian, Kra-Dai, Hmong-Mien, and Austroasiatic ancestries (Fig. 5A).

To test if the pattern observed above is more extensively applicable in East Asian populations, we then used $q p A d m^{25}$ to parse the contribution of Northern, Coastal Southern, and Inland Southern East Asian lineages, respective represented by Mongolia_N (as they have minimal Southern East Asian ancestry in admixture graph), Fujian_LN, and Mekong_N (Fig. 3B). Core Austronesians and Core Austroasiatics respective derive most of their ancestry related to Fujian_LN (66.9\%-74.3\%) and Mekong_N (58.0\%-75.2\%), suggesting that the Neolithic genomic structure in Southern East Asians has largely preserved in these modern isolated populations. In present-day Southern China, Core Kra-Dais harbors more of their ancestry related to Fujian_LN (39.0\%-53.9\%) than Mekong_N (24.9\%-32.3\%) and we also observe a similar pattern in Southeast Han Chinese (28.9\%-40.3\% for Fujian_LN and 21.8\%-25.2\% for Mekong_N), suggesting that the Kra-Dai ancestry itself primarily derives from an Austronesian-related lineage with additional Austroasiatic-related gene flow. On the contrary, Core Hmong-Mien derives more of their ancestry related to Mekong_N (32.3\%-35.3\%) than Fujian_LN (23.7\%-26.4\%), consistent with the closest phylogenetic relationship of Austroasiatic and Hmong-Mien ancestries in admixture graph (Fig. 3A). Regardless different topology between Kra-Dai and 
Austronesian ancestries suggested by qpGraph and qpAdm, both analyses indicate a consistent pattern for original geographical distribution of these four ancestries (Fig. 5A).

We used admixture- $f_{3}$ statistics ${ }^{24}$ to examine two alternative explanations for phylogenetic relationship between Kra-Dai and Austronesian ancestries. Due to small effective population size $\left(\mathrm{N}_{\mathrm{E}}\right)$ and strong genetic drift in many East Asian populations (Extended Table Fig. 1), we are usually unable to obtain significant negative $f_{3}$. Therefore, we focused on the lowest $f_{3}$ value given by different pairs of source populations and exhausted all the potential pairs. The results might not be statistically significant, but it can provide a consistent pattern if the same pair of source populations minimizes $f_{3}$ of a series of different target populations. For most of the Kra-Dai-speaking populations and Vietic speakers who have a genetic profile resembling their Kra-Dai neighbors (Extended Table 3C), the lowest $f_{3}$ achieves when one of the source population surrogates Austroasiatic ancestry (Mekong_N, Malaysia_LN, and Mlabri) and the other surrogates Austronesian ancestry (Fujian_LN and Austronesian Taiwanese), with the strongest negative signal in Kra-Dai and Vietic speakers in Mainland Southeast Asia (Muong, Nung, Lao). Since all of these populations live in the northern interior of Mainland Southeast Asia, a direct and recent gene flow from Austronesian speakers does not seem to be a feasible scenario. A more possible scenario is that the Kra-Dai ancestry itself, at least partially, is closely related to Austronesian ancestry and this favors the model suggested by $q p A d m$. The partial Austronesian-related origin for Kra-Dai ancestry is compatible with the 'Austro-Tai' hypothesis in historical linguistic ${ }^{26-28}$ that suggests a common origin of Austronesian and Kra-Dai language families, and the motif Y-chromosomal haplogroup O1a-M119 that is dominant in Neolithic Fujian individuals ${ }^{11}$ and shared by Austronesians, Kra-Dais, and Southern Han Chinese ${ }^{29}$.

The impact of distinct Southern East Asian ancestries is not limited within Southern China and further south. In the earliest samples from Yellow River Basin, coastal individuals from Early Neolithic Shandong derive all of the southern ancestry from a Fujian_LN related lineage $(32.0 \pm 6.6 \%$, Fig. 3B), consistent with their Austronesian-related ancestral component in ADMIXTURE (Fig. 1C) that largely disappears in later Northern East Asians. In contrast, inland individuals from Middle Neolithic Yangshao Culture derive all of the southern ancestry from a Mekong_N related lineage $(32.2 \pm 5.9 \%$, Fig. 3B). These genomes document that the initial isolation and genomic differentiation among geographically structured populations in Southern China is no late than Early Neolithic and demographic contact between Northern and Southern China in this period is via distinct coastal and inland routes (Fig. 5A).

Instead of a direct contribution from contemporary Neolithic Fujian population, a more plausible scenario for the Austronesian-related ancestry in Shandong Neolithic individuals they received a gene flow from a currently unsampled ancient population 
from neighboring regions like Jiangsu or Zhejiang, who in turn harbored a Fujian_LN-related lineage (Fig. 5A). This scenario is also consistent with the strong connection between Neolithic cultures in Lower Yangtze Basin, like Hemudu Culture, and contemporary Fujian, like Tanshishan Culture, to which the Fujian_LN individuals belong ${ }^{11}$. Taking genomic, linguistic, and archaeological evidence together into account, Kra-Dai ancestry likely originates from the local Austronesian-related lineage in continental Southeast China approximately ranging from Zhejiang to Guangdong with additional gene flow from an Austroasiatic-related lineage (Fig. 5A), whereas the migrants from continental Southeast China to Taiwan largely preserve the original Austronesian/Austro-Tai-related genetic profile and are responsible for the massive Austronesian expansion. However, the coexistence of Kra-Dai and Austronesian ancestry once in the continent still cannot be fully excluded in light of our analysis.

With nearly absolute southern affinity to Austroasiatic-related lineage (Fig. 3B), the genetic profile of Yangshao individuals largely persists in Late Neolithic individuals from Qijia Culture (16.0 $\pm 8.3 \%$ for Mekong_N, $1.3 \pm 10.6 \%$ for Fujian_LN) -whose expansion is supposed to parallel with the diffusion of at least some of the Tibeto-Burman languages ${ }^{30}$-and modern Tibeto-Burman speakers in Tibetan Plateau (18.9-24.2\% for Mekong_N, 0.0\% for Fujian_LN) and Tibetan-Yi Corridor like Naxi and Yi (33.7-34.1\% for Mekong_N, 0.0-1.3\% for Fujian_LN). In admixture- $f_{3}$ (Extended Data Table 3A), Tibeto-Burman populations in Tibetan-Yi Corridor and further south show a consistent pattern of two-way admixture by Sino-Tibetan and Austroasiatic ancestries. Multiple evidences suggest that populations with Austroasiatic ancestry likely distributed further north in Southwest China previously. Given the close relationship between Austroasiatic and Hmong-Mien ancestries, it is reasonable to deduct that the place of origin for both ancestries is in Southwest China (Fig. 5A) and both of them are possibly related to the Neolithic farming cultures in Middle Yangtze, e.g., Daxi Culture ${ }^{3}$, which is also consistent with that modern populations with significant Hmong-Mien-related ancestry (Fig. 1C) are distributed in Guangxi, Guizhou, and Hunan of Southwest China.

\section{Deep history of East Asian populations}

Genetic drift-based admixture graph analysis by qpGraph is informative and robust for phylogenetic reconstruction with admixture events, but it cannot estimate the time of splits and admixtures since genetic drift is not proportional to time ${ }^{24}$. Therefore, we obtained coalescent time estimation using SFS-based framework Rarecoal ${ }^{31}$ and whole genome sequences from Europeans, First Americans (Mixe, Piapoco, and Pima), Northern East Asians (Ulchi, Hezhen, and Oroqen), Coastal Southern East Asians (Ami, Atayal, and Igorot), and Inland Southern East Asians (Cambodian and Thai). We estimated that the divergence between East and West Eurasians is $~ 44,700$ BP (95\% confidence interval (CI) 44,600-44,800 BP, Fig. 3C), consistent with the time estimation in previous studies ${ }^{19,32}$ and the equal genomic relationship to East and West 
Eurasians for the $\sim 45,000$-year-old Ust'-Ishim individual ${ }^{33}$.

Earlier works have discovered that the First Americans primarily derive from an East Asian-related lineage with additional admixture with West Eurasian-related Ancient North Siberians ${ }^{15,19}$. However, it is still unclear how the East Asian-related ancestry of First Americans relates to other East Asians. Both qpGraph model (Fig. 3A) and Rarecoal model (Fig. 3C) suggest that the East Asian ancestor of First Americans represents the deepest East Asian-related lineage in all the living population who split with the common ancestor of both Northern and Southern East Asian lineages $\sim 27,700$ BP (95\% CI 27,400-27,900 BP, Fig. 3C). After that, the ancestor of Northern and Southern East Asians split with each other 23,400 BP (95\% CI 23,100-23,700 BP), which is prior to the Last Glacial Maximum (LGM) in East Asia $(\sim 21,000-15,000 \mathrm{BP})^{3}$. This implies that the differentiation between Northern and Southern East Asian lineages plausibly results from the isolation of geographically structured populations in different refugia during LGM. Within Southern East Asian lineage, the separation between Coastal and Inland Southern East Asian lineages took place $\sim 16,400$ BP (95\% CI 16,200-16,900 BP), which is contemporary with LGM and significantly earlier than the earliest farming practice in Southern China $(\sim 9,000 \mathrm{BP})^{3}$. Such a result indicates that the Neolithic transition for different Southern East Asian ancestries might result from either independent acquisition or the spread of idea without massive population replacement.

The genomic origin of Jomon hunter-gatherers in Japanese Archipelago is mysterious due to their basal East Eurasian ancestry compared with other East Asians and their additional genetic affinity to Amur Basin populations and Austronesian Taiwanese ${ }^{6,12,34}$. In our admixture graph model (Fig. 3A), there are two different layers contributing to the genetic profile of Jomon hunter-gatherers. The first layer is distantly related to Andamanese hunter-gatherers, which is likely introduced by an earlier peopling of Japanese Archipelago. The second layer is a sister lineage of Southern East Asian, which explains the genetic affinity of Jomon to other coastal East Asian populations. Compared with the large proportion of Andaman-related ancestry in Jomon hunter-gatherers $(56.5 \pm 4.8 \%)$, the small amount of Andamanese-related ancestry in ancient (6.4-11.7\%) and modern (1.0-2.1\%) populations in Amur Basin also suggests that their affinity to Jomon hunter-gatherers is more feasible to be explained by an East Asian-related ancestry than an Andamanese related ancestry. Taking both qpGraph (Fig. 3A) and Rarecoal (Fig. 3C) into account, the formation of this sister lineage to Southern East Asian is between $\sim 23,400$ BP and $\sim 16,400 \mathrm{BP}$, which mostly falls in the range of LGM. Therefore, a plausible geographic distribution for this lineage is in the continental coastal East Asia, which is largely below the sea level at present (Fig. 5A).

\section{Migrations and admixtures shaping present-day Southern Chinese}

East Asia in recent millennia has witnessed a series of massive demographic events 
that contribute to the formation of modern East Asians. Here we particularly focus on Southern China and characterize the most crucial migrations and admixtures revealed in light of our results (Fig. 5B).

\section{(D.1) Formation of Han Chinese}

Han Chinese comprise around one fifth of the world's population ${ }^{35}$. Previous studies suggest that Han Chinese is primarily formed by Yellow River Farmers (i.e., Sino-Tibetan ancestry in this study) with additional gene flow from Southern East Asian lineage ${ }^{12}$. However, it is still not fully known which specific ancestry mostly contribute to the southern ancestry of Han Chinese. In ADMIXTURE plot (Fig. 1C), both Northern and Southern Han Chinese have a similar genetic profile comprising both Sino-Tibetan and Kra-Dai ancestries, with an increase of Kra-Dai ancestry from North to South. The earliest individuals with such a genetic profile in Yellow River Basin are from Longshan Culture ( 4,000 BP) and the genetic profile in individuals resembling the genetic profile of Northern Han Chinese is found in Dacaozi_IA and Omnogovi_IA (previously assigned as Xiongnu individuals ${ }^{36}$ ) during Han Dynasty ( 4,000 BP). Formal test for pairwise genetic homogeneity conducted by qpWave (Fig. $4 \mathrm{~B})$ confirms that the genetic homogeneity between Han Dynasty individuals and any of Neolithic Shandong individuals and Inland Yellow River individuals (Yangshao_MN and Qijia_LN) is higher than the one between the latter two, consistent with a closer position for Han Dynasty individuals than Neolithic Yellow River individuals in PCA (Fig. 1A) and $q p A d m$ (Fig. 3B). This indicates that the admixture between Inland and Coastal Yellow River plays an important role in the formation of Northern Han Chinese. Regarding the formation of Sinitic Cline and Southern Han Chinese, admixture- $f_{3}$ results (Extended Table 3B) suggest that the strongest signal of admixture come from the pair of surrogates for Sino-Tibetan ancestry (Qijia_LN) and Kra-Dai (Hlai) or Austronesian ancestry (Ami, Atayal, and Kankanaey). Therefore, we conclude that the Sinitic Cline is primarily formed by massive southward migration of Northern Han Chinese and subsequent admixture with indigenous Kra-Dai speakers in Southern Chinese.

\section{(D.2) Admixture between Hmong-Mien and Kra-Dai populations}

Another major genetic cline in South China is the Hmong-Mien Cline, which comprises most of the Hmong-Mien speakers as well as neighboring Kra-Dai populations in the interior of Southern China (Fig. 5B). In ADMIXTURE plot (Fig. 1C), Hmong-Mien populations from west to east show a decrease of Hmong-Mien ancestry and an increase of Kra-Dai ancestry, suggesting that the migration of Kra-Dai speakers came from the east and constantly admixed with local Hmong-Mien populations. Meanwhile, adjacent Kra-Dai speakers of Kra (Gelao) and Kam-Sui (Dong) branches also receive significant Hmong-Mien ancestry, indicating a bidirectional gene flow. Admixture time estimation performed by ALDER (Extended Data Table 4) shows that the admixture of Hmong-Mien Cline happened 24-46 
generations ago overlapping Tang Dynasty to Yuan Dynasty.

\section{(D.3) Spread of Kra-Dai ancestry in Mainland Southeast Asia}

Besides the contribution to Han Chinese and Hmong-Mien populations, Kra-Dai ancestry also has a strong impact to Mainland Southeast Asia in recent two millennia. The earliest genomic document for the arrival of Kra-Dai ancestry in Mainland Southeast Asia is Bronze Age individuals from northern Vietnam ( 2,000 BP, Fig. 1C). Further extensive admixture between populations with more Kra-Dai ancestry and more Austroasiatic ancestry that arrived earlier largely explain the more obvious discrepancy between gene and language in Mainland Southeast Asians than other Southern East Asians. Especially, it is evident in PCA (Fig. 1A and B), ADMIXTURE (Fig. 1C), and outgroup- $f_{3}$ (Fig. 2A) that Austroasiatic-speaking Kinh and Muong of the Vietic branch have a more similar genetic profile with Kra-Dai speakers in South China than other Austroasiatic speakers with a more typical 'Austroasiatic' genetic profile, suggesting a language shift from incoming Kra-Dai language to local Austroasiatic language as a possible mechanism.

\section{(D.4) Genomic origin of Tibeto-Burman-speaking Mainland Southeast Asians}

The special Y-chromosomal haplogroup F2-M427 in Lahu ${ }^{37}$ and many other Tibeto-Burman populations in Mainland Southeast Asia raise further question for their genomic origin. In ADMIXTURE plot (Fig. 1C), we find that Tibeto-Burman speakers in Mainland Southeast Asia (Lahu from China and Vietnam, Sila, HaNhi (Hani), and Cong) majorly have a genetic profile comprising Sino-Tibetan and Austroasiatic ancestries, with a consistent pattern in qpAdm (36.7-50.1\% for Mekong_N, 7.9-19.1\% for Fujian_LN, Fig. 3B). Both results suggest that the Tibeto-Burman-speaking migrants from the north and their admixture with local Austroasiatic speakers form the genetic profile of present-day Lahu and neighboring Tibeto-Burman speakers. We also observe that such a genetic profile had occurred in the Iron Age Thailand individuals $\sim 1,700 \mathrm{BP}$, with their genetic homogeneity with present-day Tibeto-Burman speakers in Mainland Southeast Asia confirmed by qpWave (Fig. 4A).

\section{DISCUSSION}

In this study, we provide a comprehensive and detailed landscape for the genomic history of East Asians, especially Southern Chinese. We retrieve the deep origin and structure for the main ancestral groups in East Asia (Fig. 5A) and we document human migrations and admixtures that form the genomic and linguistic scenario in present-day Southern China (Fig. 5B). We predict that future ancient genomes from the interior of Southern China will further improve and examine the demographic framework of Southern East Asians established in our study. 


\section{METHODS}

\section{Sampling and genotyping}

We collected blood and saliva samples from 211 unrelated individuals affiliated to Miao, Zhuang, and Han ethnicities from 30 subgroups in Guangxi and Yunnan of Southern China. Further linguistic and geographic information of these subgroups was described in Extended Data Table 1. The study was approved by Ethical Committee of Youjiang Medical University for Nationalities and all the processes involved were consistent with the corresponding ethical principles. All the participants read and signed the informed content. Then, we achieved the genotyped data of these samples using the Affymetrix WeGene V1 Array, which includes 492,683 genome-wide SNPs and is referred to as ' $500 \mathrm{~K}$ dataset' elsewhere in this paper. Other experimental and bioinformatic procedures for genotyping were consistent with the protocol documented in previous studies ${ }^{38,39}$.

\section{Dataset arrangement}

We merged our $500 \mathrm{~K}$ dataset with published present-day and ancient genomic data $^{6-9,11,12,17,18,24,32,33,39-56}$, resulting in two types of panel: (1) merged panel of 500K dataset and 1240K-capture dataset (1,233,013 SNPs, including all the ancient samples and shotgun-sequenced modern samples) with 372,929 SNPs, which is for the purpose of maximizing the number of informative SNPs; (2) merged panel of the panel above and 600K Human Origin Array dataset (597,573 SNPs, including other modern samples) with 110,931 SNPs, which is for the purpose of maximizing the number and size of populations. For Rarecoal analysis, we used whole genome sequences from Simons Genome Diversity Project (SGDP) ${ }^{47}$.

\section{Abbreviations}

We used the following abbreviations throughout our article: LP, Late Pleistocene; M, Mesolithic; N, Neolithic; EN, Early Neolithic; MN, Middle Neolithic; LN, Late Neolithic; BA, Bronze Age; IA, Iron Age; o, outlier; HG, hunter-gatherer; MSEA, Mainland Southeast Asia; ISEA, Island Southeast Asia; AN, Austronesian; AA, Austroasiatic; HM, Hmong-Mien; KD, Kra-Dai; HO, Human Origin Array. Particularly, Mongolia_N refers to Mongolia_N_East unless otherwise specified.

\section{Principal component analysis (PCA)}

We performed PCA by smartpca program of EIGENSOFT ${ }^{13}$ with parameters lsqproject: YES, shrinkmode: YES, numoutlieriter: 0, killr2: YES, r2thresh: 0.4, r2genlim: 0.1. We only used modern samples to construct PCs with ancient samples projected.

\section{ADMIXTURE analysis}

We first used PLINK ${ }^{57}$ to prune the linkage disequilibrium by parameters --indep-pairwise 20020 0.4. Then, we ran ADMIXTURE ${ }^{14}$ with default parameters from $K=2$ to 20 . We reported the result when $K=10$ as it reaches the lowest cross 
error (Extended Data Fig. 2).

\section{$f$-statistics}

We used ADMIXTOOLS ${ }^{24}$ to compute $f_{3}$-statistics and D-statistics (Supplementary Information Table 2) with the estimation of standard error by jackknife. We used Mbuti as outgroup for Eurasian populations in outgroup $-f_{3}$.

\section{Admixture graph modelling by qpGraph}

We used qpGraph program of ADMIXTOOLS ${ }^{24}$ to reconstruct the phylogeny with admixture by default parameters. We exhausted different feasible graph models and select the optimal model based on maximum $|\mathrm{Z}|$-score and likelihood.

\section{Admixture coefficient modelling by $q p A d m$}

We used $q p A d m^{25}$ to compute the ancestral coefficient based on $\mathrm{f}$-statistics to different outgroups. We chose the optimal model for a given target population based on the following criteria, sorted by priority. (1) The model is feasible if and only if all the ancestral coefficients fall within the range $[0,1]$. (2) The full model is chosen if both full and nested models are feasible. (3) If the full model is infeasible and more than one nested models are feasible, then the nested model with the highest $p$-value is chosen. We applied 'proximal model' and 'distal model' ${ }^{50}$ to model the ancestry contribution in different time period.

Proximal model. We used Mongolia_N_East, Mekong_N (pooled population of Vietnam_N, Laos_LN_BA.SG, and Laos_BA.WGC), and Fujian_LN as proxies for Northern East Asian, Inland Southern East Asian, and Coastal Southern East Asian ancestries. The initial outgroups that we used are: South_Africa_2000BP.SG, Ust_Ishim.DG, Yana_UP.SG, Alaska_LP, Kolyma_M, Andaman_HG, Jomon_HG, Liangdao2_EN, Malaysia_LN.SG. We also used the 'rotating' strategy ${ }^{41}$ to further verify the nested models, in which we moved one of the proxies into the set of outgroups by turn. Since there is no high-coverage ancient sample that is sufficiently older than Mekong_N in Austroasiatic-related lineage, we expediently used Malaysia_LN.SG who closely related to Mekong_N as outgroup but we caution that it tends to underestimate $p$-values. Therefore, we also calculated relative likelihood ratios to test if a full model is better than its nested models and we find the ratios are usually higher than 100. Original results of proximal model are presented in Supplementary Information Table 1.

Distal model. We used Mongolia_N_East and Andaman_HG as proxies for East Asian and Andamanese-related ancestries. We used the following outgroups in distal model: South_Africa_2000BP.SG, Ust_Ishim.DG, Georgia_Kotias.SG, Loschbour.DG, Yana_UP.SG, Botai_EN, Russia_BA_Okunevo.SG, Russia_EHG_Karelia, Tianyuan, Papuan.DG, Mala.DG, Australian.DG, Hoabinhian. 


\section{Genetic homogeneity testing by qpWave}

We used $q p W a v e^{58}$ to formally test if pairwise populations are homogeneous in relation to a series of outgroups. We used following outgroups for Southern East Asian populations: South_Africa_2000BP.SG, Ust_Ishim.DG, Loschbour.DG, Yana_UP.SG, Alaska_LP, Kolyma_M, Andaman_HG, Liangdao2_EN, Jomon_HG, Malaysia_LN.SG, Nepal_LN_BA_IA, DevilsCave_N, Shamanka_EN. We used following outgroups for Northern East Asian populations: South_Africa_2000BP.SG, Ust_Ishim.DG, Loschbour.DG, Yana_UP.SG, Alaska_LP, Kolyma_M, Andaman_HG, Liangdao2_EN, Jomon_HG, Malaysia_LN.SG, Nepal_LN_BA_IA, DevilsCave_N, Shamanka_EN.

\section{Demographic modelling implemented by Rarecoal}

We used Rarecoal program ${ }^{31,54}$ to obtain a SFS-based phylogeny with time estimates using default parameters. We used mutation rate in every generation ${ }^{59}$ of $1.25 \times 10^{-8}$ and 29 years per generation ${ }^{60}$ to scale the time.

\section{Admixture time estimation by ALDER}

We used linkage disequilibrium-based $\mathrm{ALDER}^{61}$ to estimate admixture time of Hmong-Mien Cline using default parameters and checkmap: YES, mindis: 0.005, binsize: 0.0001 .

\section{Identity-by-descent (IBD) analysis}

We first used SHAPEIT ${ }^{62}$ to phase the modern individuals in our dataset. Then we used Refine IBD software ${ }^{16}$ to obtain pairwise sharing of IBD segments among individuals. We normalized the results in population level by dividing it by the product of the sample size of pairwise populations.

\section{Correlation between $\mathrm{N}_{\mathrm{E}}$ and $\mathrm{F}_{\mathrm{ST}}$ to Ust'-Ishim}

We used the formula in Palamara et al. ${ }^{63}$ to estimate $N_{E}$ from shared IBD within a population. We computed $\mathrm{F}_{\mathrm{ST}}$ by smartpca ${ }^{13}$ with default parameters and fstonly: YES.

\section{LGM coastline in East Asia}

The coastline during LGM period in East Asia shown in Fig. 5A is adopted from Ray et al.. ${ }^{64}$ 


\section{REFERENCES}

1 Barnes, G. L. Archaeology of East Asia: the rise of civilization in China, Korea and Japan. (Oxbow Books, 2015).

2 Stevens, C. J. \& Fuller, D. Q. The spread of agriculture in Eastern Asia: Archaeological bases for hypothetical farmer/language dispersals. Language Dynamics and Change 7, 152-186 (2017).

3 Liu, L. \& Chen, X. The archaeology of China: from the late Paleolithic to the early Bronze Age. (Cambridge University Press, 2012).

4 Gutaker, R. M. et al. Genomic history and ecology of the geographic spread of rice. Nature Plants 6, 492-502 (2020).

5 Diamond, J. \& Bellwood, P. Farmers and their languages: The first expansions. Science 300, 597-603, doi:10.1126/science.1078208 (2003).

6 McColl, H. et al. The prehistoric peopling of Southeast Asia. Science 361, 88-92 (2018).

7 Lipson, M. et al. Ancient genomes document multiple waves of migration in Southeast Asian prehistory. Science 361, 92-95 (2018).

8 Skoglund, P. et al. Genomic insights into the peopling of the Southwest Pacific. Nature 538, 510 (2016).

9 Lipson, M. et al. Population turnover in Remote Oceania shortly after initial settlement. Current Biology 28, 1157-1165. e1157 (2018).

10 Lipson, M. et al. Three Phases of Ancient Migration Shaped the Ancestry of Human Populations in Vanuatu. Current Biology (2020).

11 Yang, M. A. et al. Ancient DNA indicates human population shifts and admixture in northern and southern China. Science (2020).

12 Wang, C.-C. et al. The Genomic Formation of Human Populations in East Asia. bioRxiv (2020).

13 Patterson, N., Price, A. L. \& Reich, D. Population structure and eigenanalysis. PLoS genetics 2, e190 (2006).

14 Alexander, D. H., Novembre, J. \& Lange, K. Fast model-based estimation of ancestry in unrelated individuals. Genome research 19, 1655-1664 (2009).

15 Raghavan, M. et al. Upper Palaeolithic Siberian genome reveals dual ancestry of Native Americans. Nature 505, 87 (2014).

16 Browning, B. L. \& Browning, S. R. Improving the accuracy and efficiency of identity-by-descent detection in population data. Genetics 194, 459-471 (2013).

17 Ning, C. et al. Ancient genomes from northern China suggest links between subsistence changes and human migration. Nature communications 11, 1-9 (2020).

18 Siska, V. et al. Genome-wide data from two early Neolithic East Asian individuals dating to 7700 years ago. Science advances 3, e1601877 (2017).

19 Sikora, M. et al. The population history of northeastern Siberia since the Pleistocene. Nature, doi:10.1038/s41586-019-1279-z (2019).

20 Campbell, L. Historical linguistics. (Edinburgh University Press, 2013). 
21 Bouckaert, R. et al. Mapping the origins and expansion of the Indo-European language family. Science 337, 957-960 (2012).

22 Ratliff, M. S. Hmong-Mien language history. (Research School of Pacific and Asian Studies, The Australian National University, 2010).

23 Luo, Y. in The Tai-Kadai Languages 25-44 (Routledge, 2004).

24 Patterson, N. J. et al. Ancient admixture in human history. Genetics, genetics. 112.145037 (2012).

25 Haak, W. et al. Massive migration from the steppe was a source for Indo-European languages in Europe. Nature 522, 207 (2015).

26 Blench, R. M. in Unearthing Southeast Asia's past: Selected papers from the 12th international conference of the European Association of Southeast Asian Archaeologists. 3-15.

27 Ostapirat, W. in 23rd Annual Meeting of the Southeast Asian Linguistic Society, Chulalongkorn University.

28 Sagart, L. The higher phylogeny of Austronesian and the position of Tai-Kadai. Oceanic Linguistics 43, 411-444 (2004).

29 Sun, J. et al. Paternal gene pool of Malays in Southeast Asia and its applications for the early expansion of Austronesians. American Journal of Human Biology, e23486 (2020).

30 Zhang, M., Yan, S., Pan, W. \& Jin, L. Phylogenetic evidence for Sino-Tibetan origin in northern China in the Late Neolithic. Nature, doi:10.1038/s41586-019-1153-z (2019).

31 Schiffels, S. et al. Iron age and Anglo-Saxon genomes from East England reveal British migration history. Nature communications 7, 1-9 (2016).

32 de Barros Damgaard, P. et al. The first horse herders and the impact of early Bronze Age steppe expansions into Asia. Science 360, eaar7711 (2018).

$33 \mathrm{Fu}, \mathrm{Q}$. et al. Genome sequence of a 45,000-year-old modern human from western Siberia. Nature 514, 445 (2014).

34 Gakuhari, T. et al. Ancient Jomon genome sequence analysis sheds light on migration patterns of early East Asian populations. Communications biology 3, 1-10 (2020).

35 Minahan, J. B. Ethnic Groups of North, East, and Central Asia: An Encyclopedia. (ABC-CLIO, 2014).

36 de Barros Damgaard, P. et al. 137 ancient human genomes from across the Eurasian steppes. Nature 557, 369 (2018).

37 Black, M. L., Wise, C. A., Wang, W. \& Bittles, A. H. Combining genetics and population history in the study of ethnic diversity in the People's Republic of China. Human Biology 78, 277-293 (2006).

38 Huang, X. et al. The genetic assimilation in language borrowing inferred from Jing People. American journal of physical anthropology 166, 638-648 (2018).

39 He, G. et al. Inferring the population history of Tai-Kadai-speaking people and southernmost Han Chinese on Hainan Island by genome-wide array genotyping. European Journal of Human Genetics, 1-13 (2020).

40 Schlebusch, C. M. et al. Southern African ancient genomes estimate modern 
human divergence to 350,000 to 260,000 years ago. Science $\mathbf{3 5 8}$, 652-655 (2017).

41 Skoglund, P. et al. Reconstructing prehistoric African population structure. Cell 171, 59-71. e21 (2017).

42 Sikora, M. et al. The population history of northeastern Siberia since the Pleistocene. bioRxiv, 448829 (2018).

43 Moreno-Mayar, J. V. et al. Terminal Pleistocene Alaskan genome reveals first founding population of Native Americans. Nature 553, 203 (2018).

44 Moreno-Mayar, J. V. et al. Early human dispersals within the Americas. Science 362, eaav2621 (2018).

45 Lazaridis, I. et al. Ancient human genomes suggest three ancestral populations for present-day Europeans. Nature 513, 409 (2014).

46 Lazaridis, I. et al. Genomic insights into the origin of farming in the ancient Near East. Nature 536, 419 (2016).

47 Mallick, S. et al. The Simons genome diversity project: 300 genomes from 142 diverse populations. Nature 538, 201 (2016).

48 Jeong, C. et al. The genetic history of admixture across inner Eurasia. Nature Ecology \& Evolution, doi:10.1038/s41559-019-0878-2 (2019).

49 Jeong, C. et al. Long-term genetic stability and a high-altitude East Asian origin for the peoples of the high valleys of the Himalayan arc. Proceedings of the National Academy of Sciences 113, 7485-7490 (2016).

50 Narasimhan, V. M. et al. The formation of human populations in South and Central Asia. Science 365, eaat7487 (2019).

51 Yang, M. A. et al. 40,000-year-old individual from Asia provides insight into early population structure in Eurasia. Current Biology 27, 3202-3208. e3209 (2017).

52 Liu, D. et al. Extensive ethnolinguistic diversity in Vietnam reflects multiple sources of genetic diversity. Molecular biology and evolution 37, 2503-2519 (2020).

53 Jones, E. R. et al. Upper Palaeolithic genomes reveal deep roots of modern Eurasians. Nature communications 6, 1-8 (2015).

54 Flegontov, P. et al. Palaeo-Eskimo genetic ancestry and the peopling of Chukotka and North America. Nature, 1 (2019).

55 Skoglund, P. et al. Genetic evidence for two founding populations of the Americas. Nature 525, 104-108 (2015).

56 Consortium, G. P. A global reference for human genetic variation. Nature 526, 68 (2015).

57 Purcell, S. et al. PLINK: a tool set for whole-genome association and population-based linkage analyses. The American journal of human genetics 81, 559-575 (2007).

58 Reich, D. et al. Reconstructing Native American population history. Nature 488, 370-+, doi:10.1038/nature11258 (2012).

59 Scally, A. \& Durbin, R. Revising the human mutation rate: implications for understanding human evolution. Nature Reviews Genetics 13, 745-753 (2012). 
60 Fenner, J. N. Cross $\square$ cultural estimation of the human generation interval for use in genetics $\square$ based population divergence studies. American Journal of Physical Anthropology: The Official Publication of the American Association of Physical Anthropologists 128, 415-423 (2005).

61 Loh, P.-R. et al. Inferring admixture histories of human populations using linkage disequilibrium. Genetics 193, 1233-1254 (2013).

62 O'Connell, J. et al. A general approach for haplotype phasing across the full spectrum of relatedness. PLoS Genet 10, e1004234 (2014).

63 Palamara, P. F., Lencz, T., Darvasi, A. \& Pe'er, I. Length distributions of identity by descent reveal fine-scale demographic history. The American journal of human genetics 91, 809-822 (2012).

64 Ray, N. \& Adams, J. M. A GIS-based vegetation map of the world at the last glacial maximum (25,000-15,000 BP). Internet Archaeology (2001). 
Figure 1. Genetic structure of East Asians. (A to B) PCA for (A) all the East Asians and (B) Southern East Asians. We projected ancient samples to principal components constructed by modern samples. $(\mathbf{C})$ Unsupervised ADMIXTURE plot at $\mathrm{K}=10$, identifying six major ancestries in East Asia: orange, Northeast Asia/ Tungusic-related; red, Sino-Tibetan-related; blue, Austronesian-related; green, Kra-Dai-related; yellow, Hmong-Mien-related; purple, Austroasiatic-related.

A

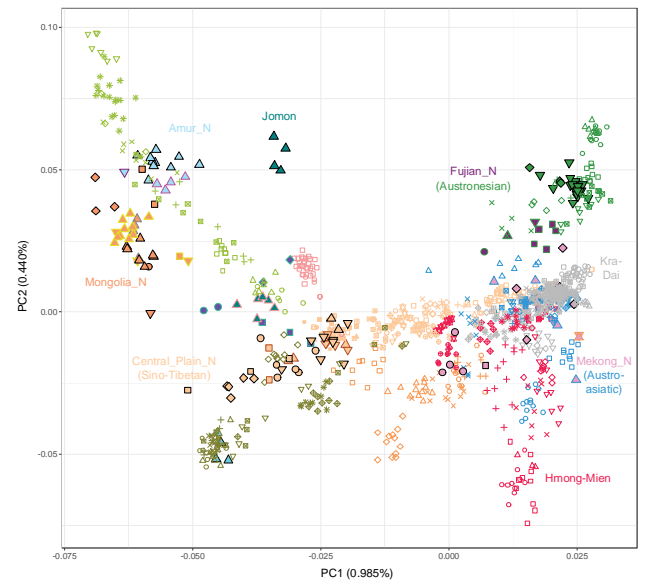

B

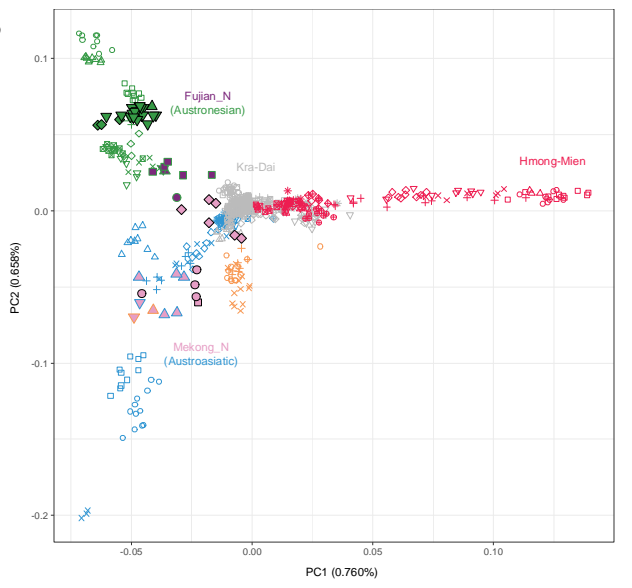

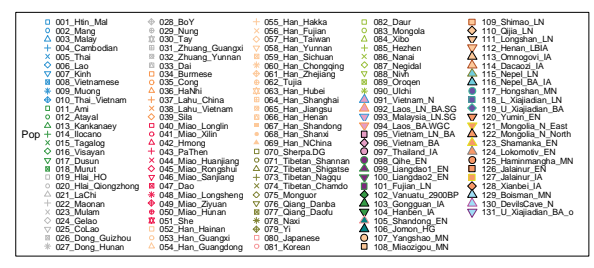

C

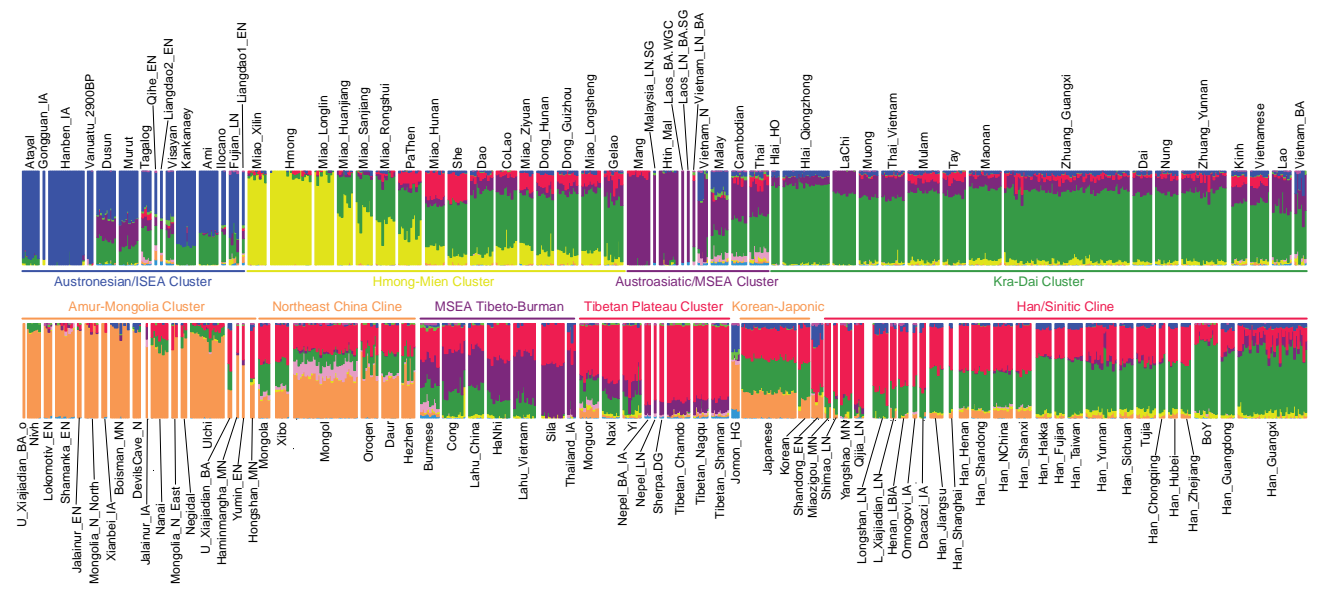


bioRxiv preprint doi: https://doi.org/10.1101/2020 11.08 373225; this version posted November 8,2020 . The copyright holder for this preprint (which was not certified by peer review) is the author/funder, who has granted bioRxiv a license to display the preprint in perpetuity. It is made available under aCC-BY-NC 4.0 International license.

Figure 2. Quantitative measurement for pairwise genetic affinity. (A) Outgroup- $f_{3}$ in the form $f_{3}$ (Mbuti; X, Y) measuring shared genetic drift between pairwise ancient and modern East Asian populations. (B to $\mathbf{C}$ ) Normalized haplotype sharing based on (B) the number and $(\mathrm{C})$ the total length (unit: $\mathrm{cM}$ ) of shared IBD chunks for pairwise modern East Asian populations.

A

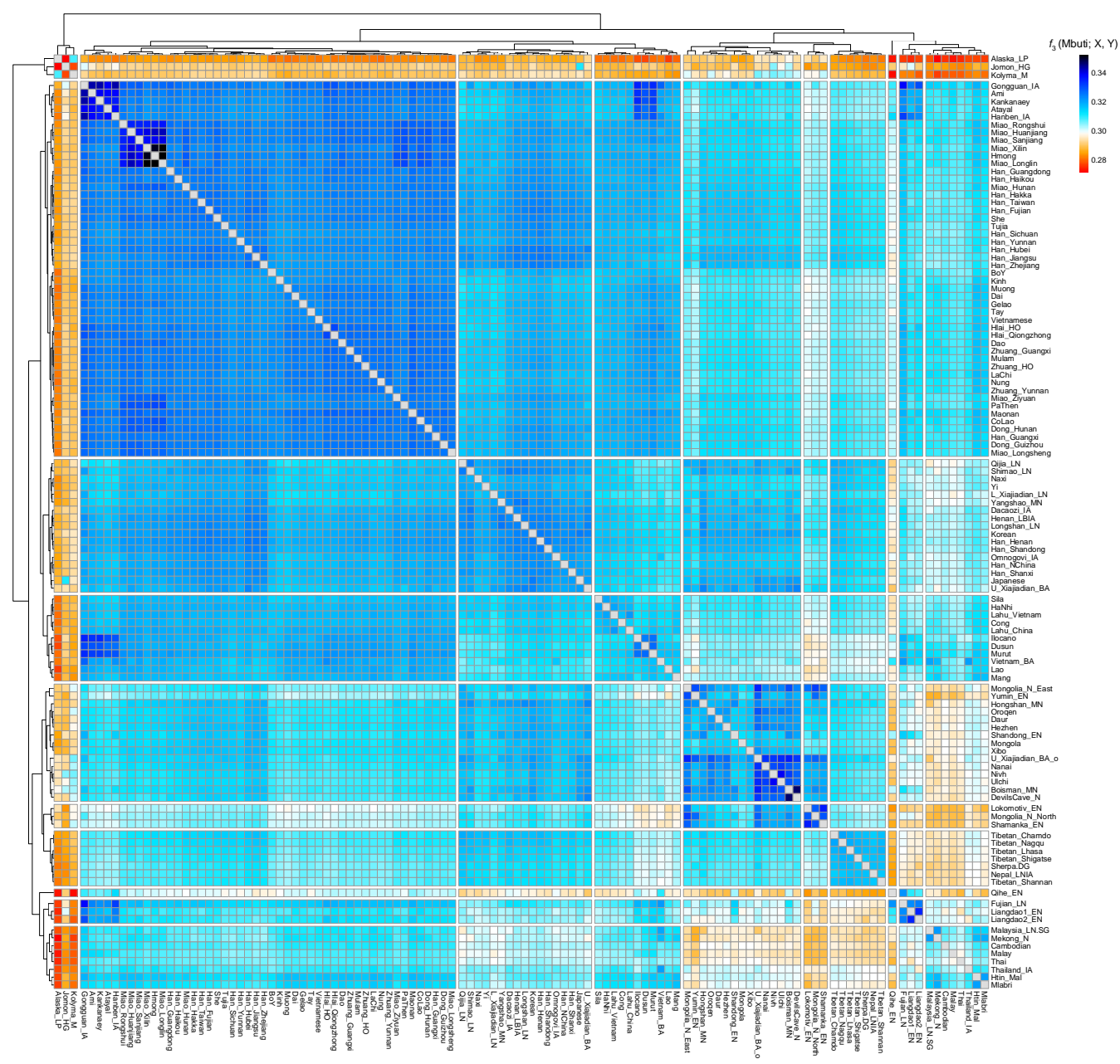


bioRxiv preprint doi: https://doi. org/10.1101/202011.08 373225 t this version posted November 8,2020 . The copyright holder for this preprint (which was not certified by peer review) is the author/funder, who has granted bioRxiv a license to display the preprint in perpetuity. It is made available under aCC-BY-NC 4.0 International license.

B

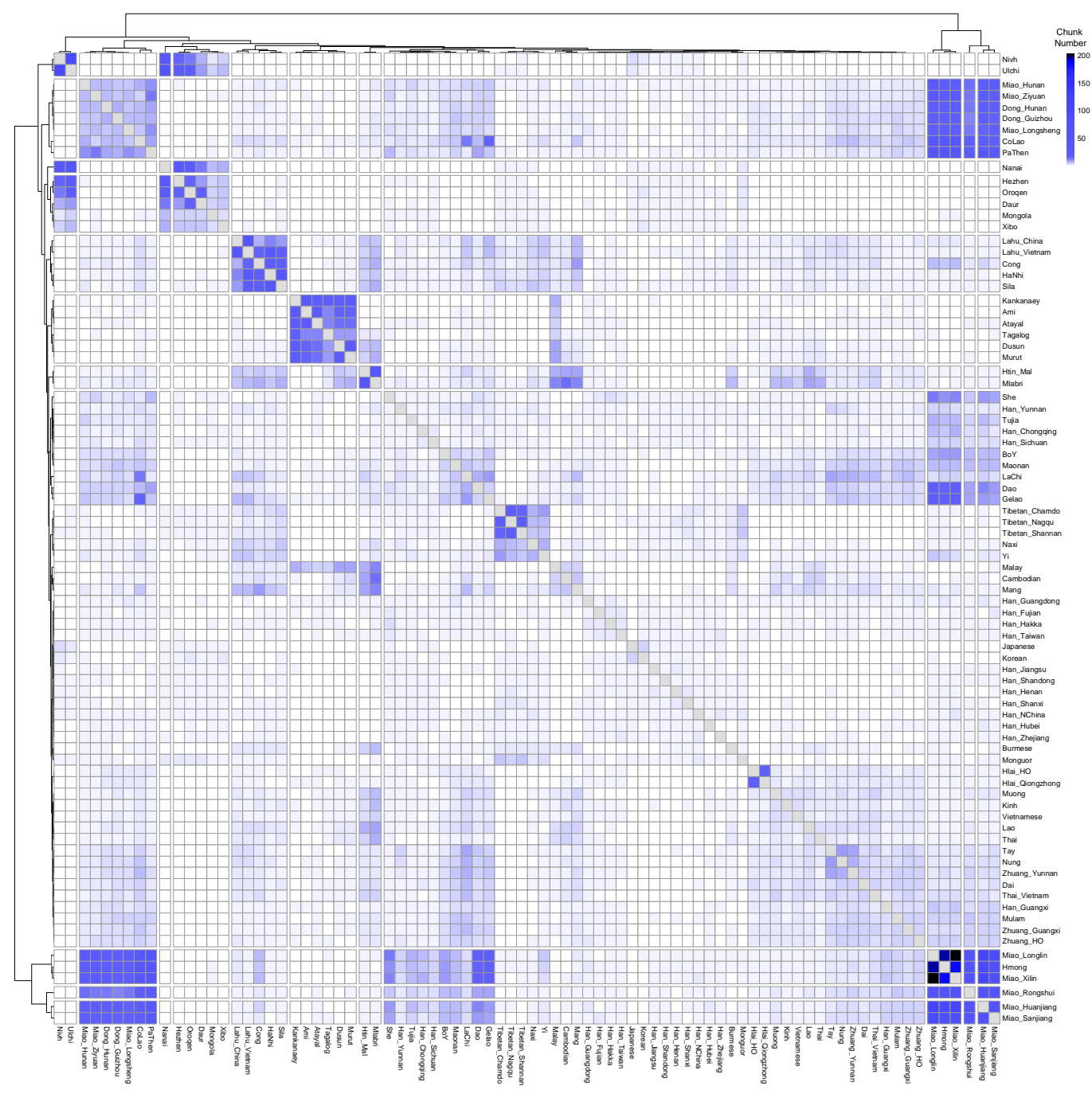


bioRxiv preprint doi: https://doi. org/10.1101/202011.08 373225 t this version posted November 8,2020 . The copyright holder for this preprint (which was not certified by peer review) is the author/funder, who has granted bioRxiv a license to display the preprint in perpetuity. It is made available under aCC-BY-NC 4.0 International license.

C

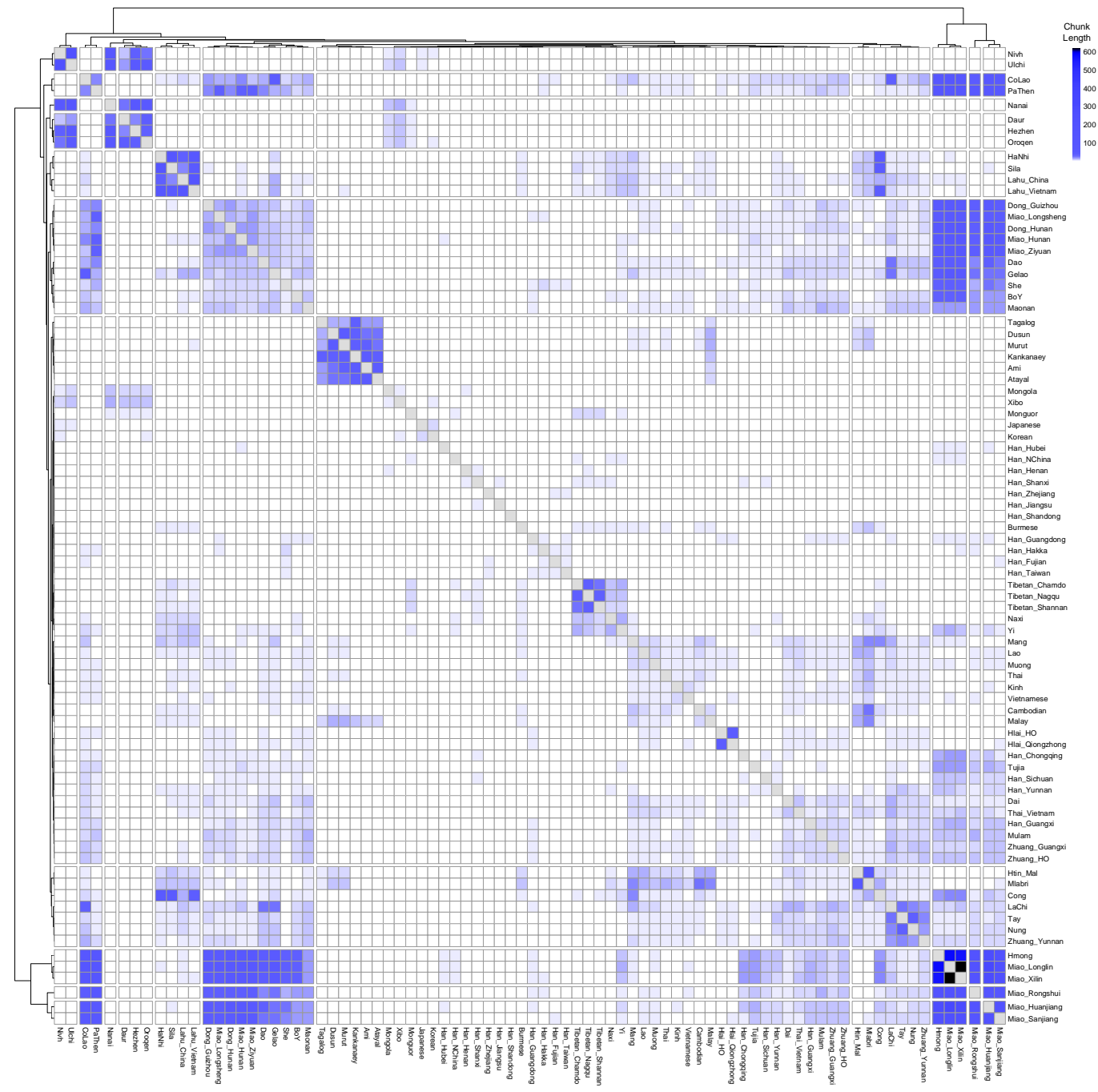


Figure 3. Demographic modelling for deep history of East Asians. (A) Optimal qpGraph admixture model for the phylogenetic relationship among the surrogates for major ancestries in East Asia. Alaska_LP, Mongolia_N/Boisman_MN, Sherpa, Hanben_IA, Hlai_Qiongzhong, Miao_Longlin, and MSEA_N respectively surrogate First Americans, Northeast Asian, Sino-Tibetan, Austronesian, Kra-Dai, Hmong-Mien, and Austroasiatic ancestries. Drift along each edge are multiplied by 1,000. (B) Three-source $q p A d m$ models the contribution of Northern East Asian (represented by Mongolia_N), Coastal Southern East Asian (represented by Fujian_LN), and Inland Southern East Asian (represented by Mekong_N) lineages in ancient and present-day East Asians. (C) Coalescent analysis using SFS of rare alleles to calibrate the time of the major splits in East Asians (implemented by Rarecoal). We used whole genome sequences from 56 individuals in this analysis. kya, thousand years ago.

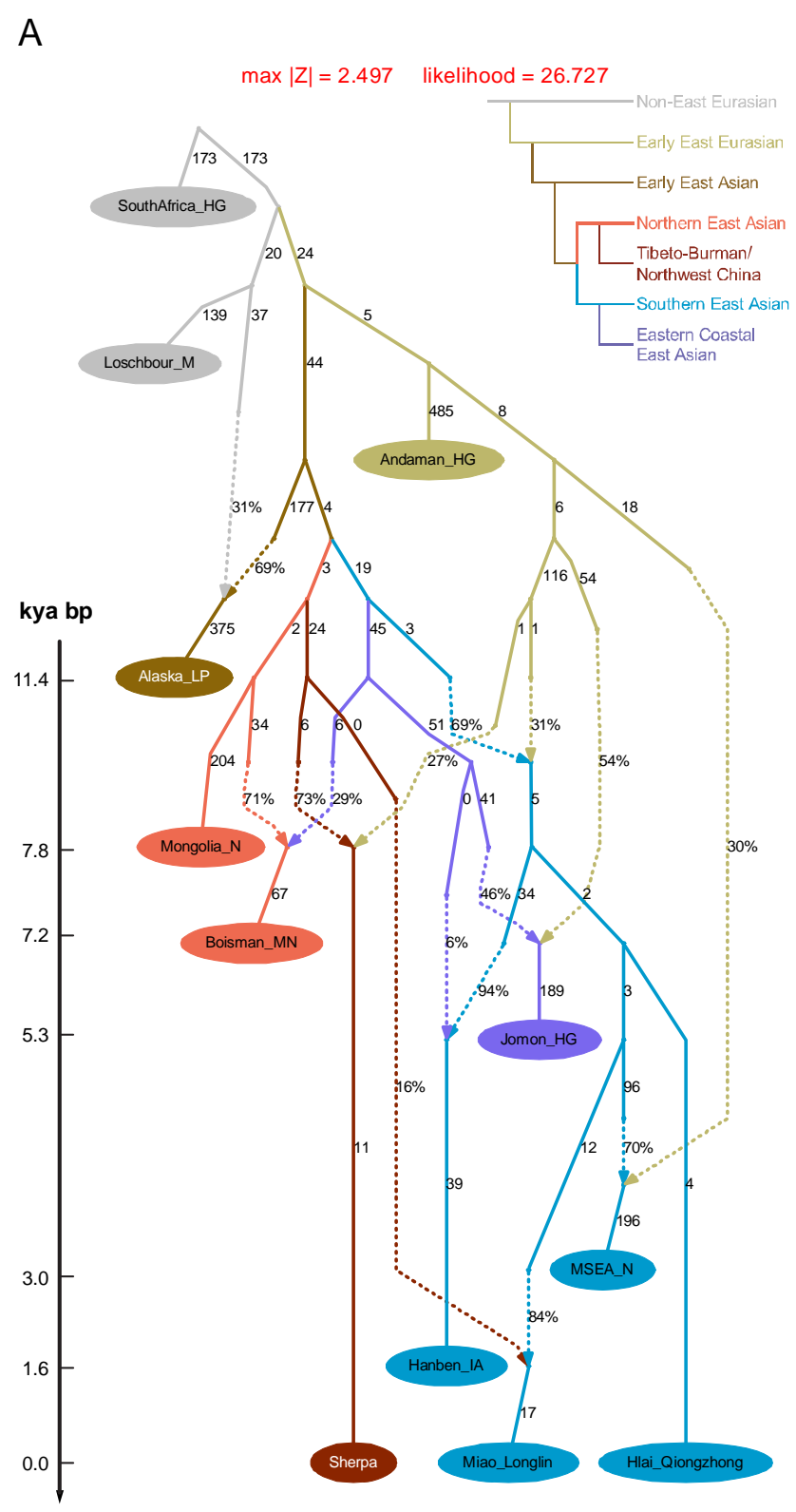


bioRxiv preprint doi: https://doi.org/10.1101/2020.11.08.373225; this version posted November 8, 2020. The copyright holder for this preprint (which was not certified by peer review) is the author/funder, who has granted bioRxiv a license to display the preprint in perpetuity. It is made available under aCC-BY-NC 4.0 International license.

B

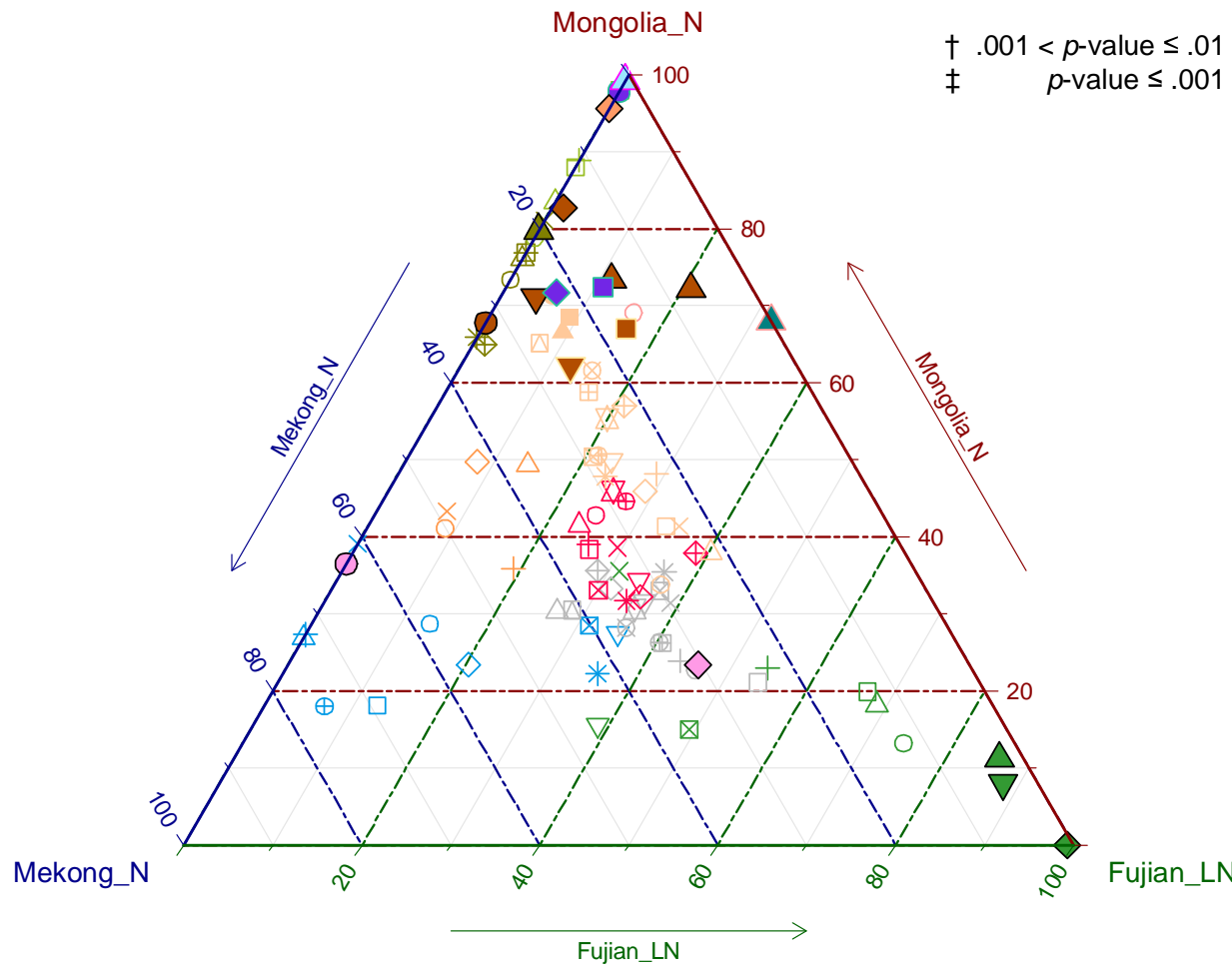

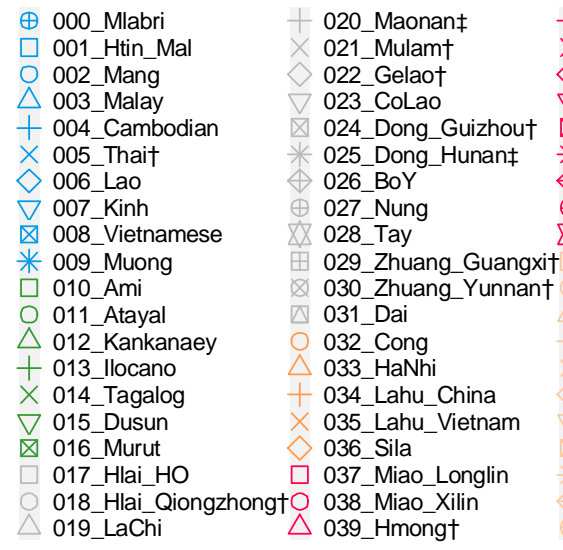

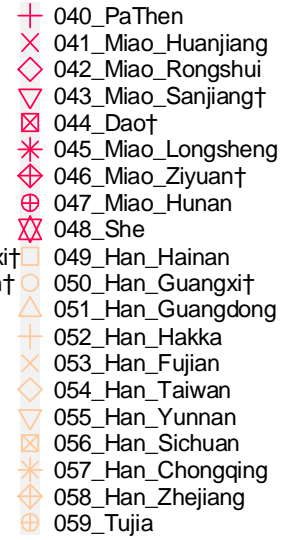

060_Han Hubei 061_Han_Shanghai 062 Han Jiangsu 063_Han_Henan 064 Han Shandong 065 Han Shanxi 066_Han_NChina $\square$ 067_Sherpa.DG 068 Tibetan Shannanł> 088 Qijia LN $\triangle 069$ Tibetan_Shigatse† $\square$ 089_Longshan LN + 070_Tibetan_Nagqu $>090 \_$Henan_LBIA $\times$ 071_Tibetan_Chamdo $\triangle 091$ Omnogovi_IA * 072_Naxi $\leftrightarrow 073$ Yi 074_Korean 075_Daur 076 Mongola $077^{-}$Xibo +078 - Xibo 凶 079_Oroqen 092_Dacaozi IA 093 Nepel LNIA 094_Hongshan_MN 095_L_Xiajiadian_LN 096_U_Xiajiadian_BA 097 Xianbei IA

098_DevilsCave_N 
bioRxiv preprint doi: https://doi.org/10.1101/2020.11.08.373225; this version posted November 8, 2020. The copyright holder for this preprint (which was not certified by peer review) is the author/funder, who has granted bioRxiv a license to display the preprint in perpetuity. It is made available under aCC-BY-NC 4.0 International license.

C

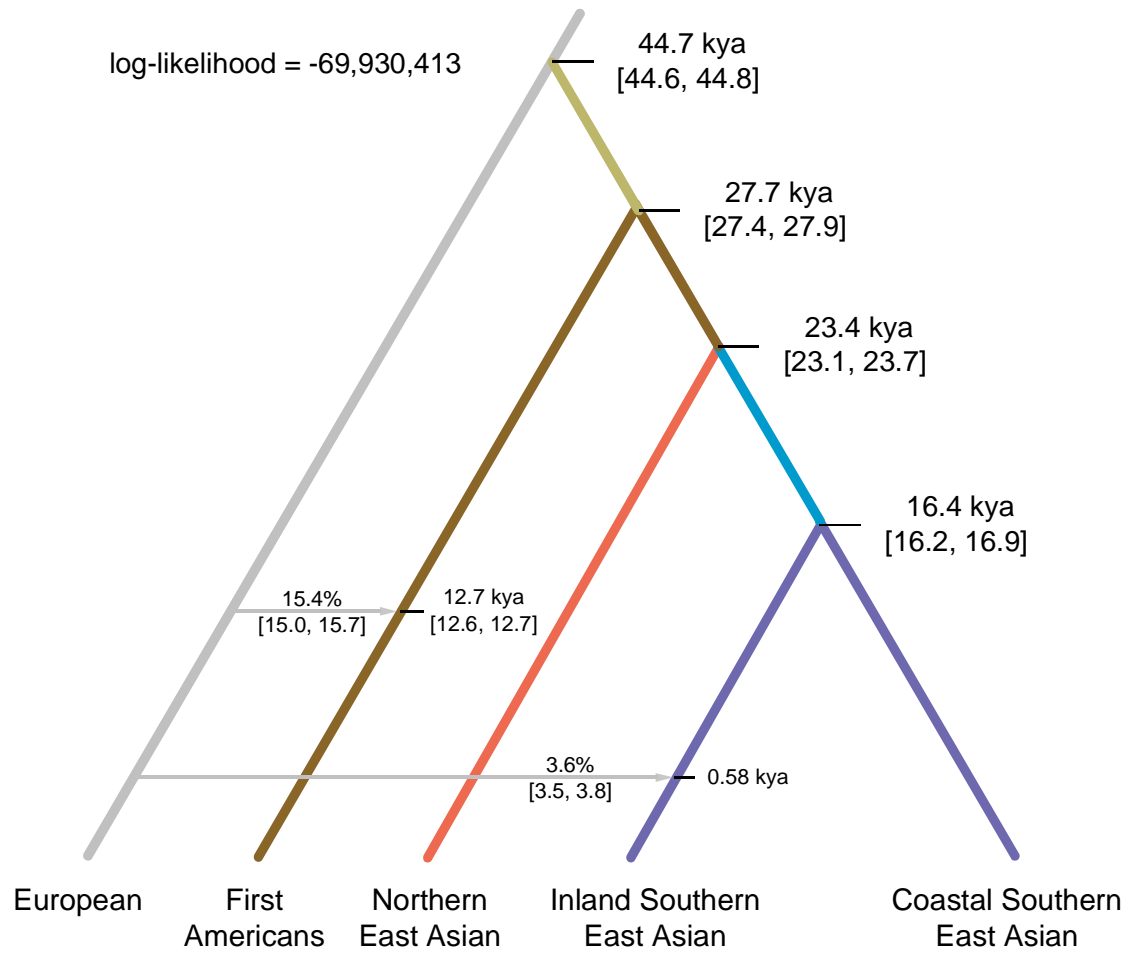


bioRxiv preprint doi: https://doi.org/10.1101/2020.11.08.373225; this version posted November 8, 2020. The copyright holder for this preprint (which was not certified by peer review) is the author/funder, who has granted bioRxiv a license to display the preprint in perpetuity. It is made available under aCC-BY-NC 4.0 International license.

Figure 4. Genetic homogeneity of pairwise populations. Heatmaps show negative logarithms for $p$-values of pairwise qpWave in (A) Southern East Asians and (B) Northern East Asians.

A

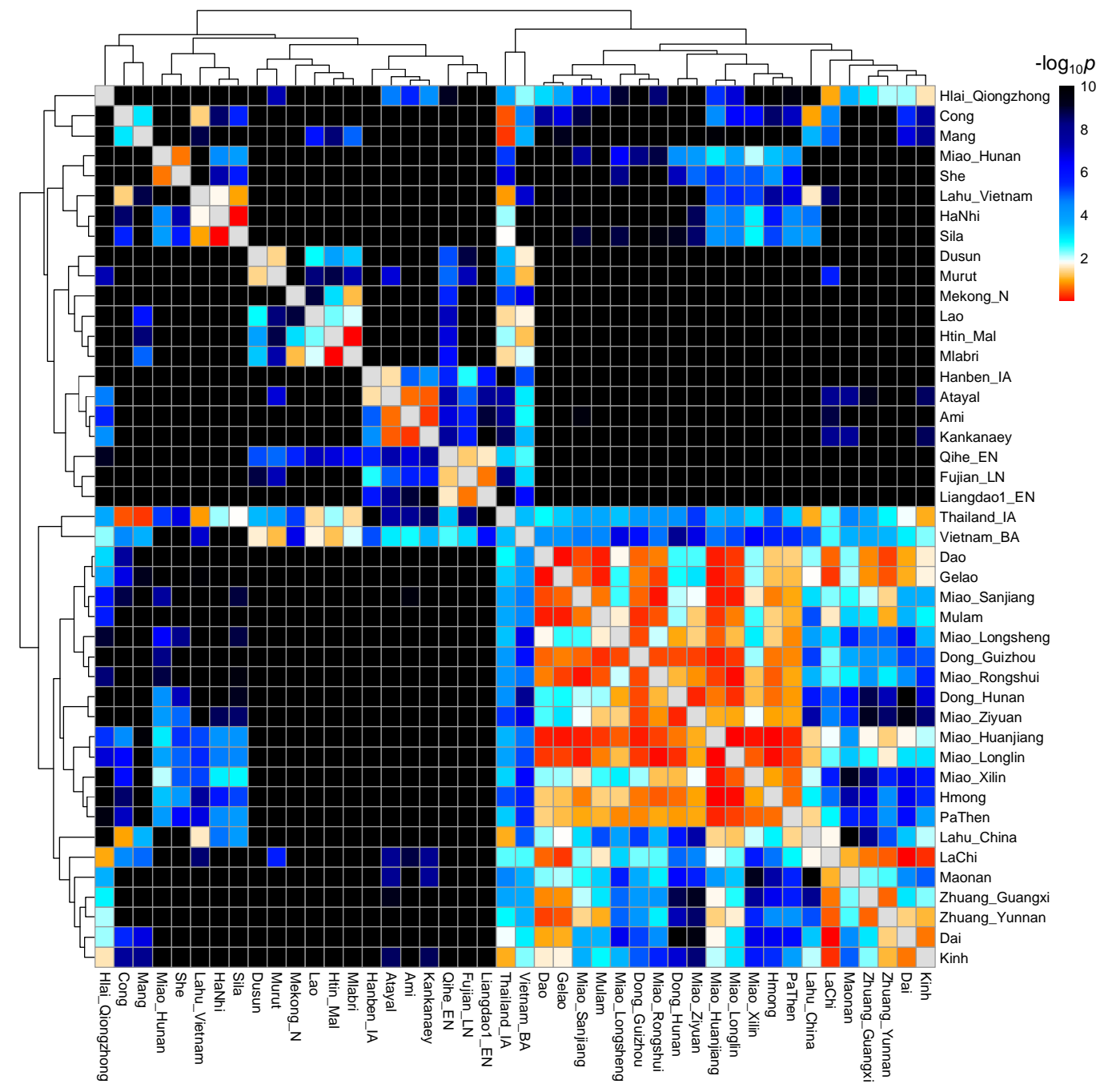


bioRxiv preprint doi: https://doi.org/10.1101/2020.11.08.373225; this version posted November 8, 2020. The copyright holder for this preprint (which was not certified by peer review) is the author/funder, who has granted bioRxiv a license to display the preprint in perpetuity. It is made available under aCC-BY-NC 4.0 International license.

B

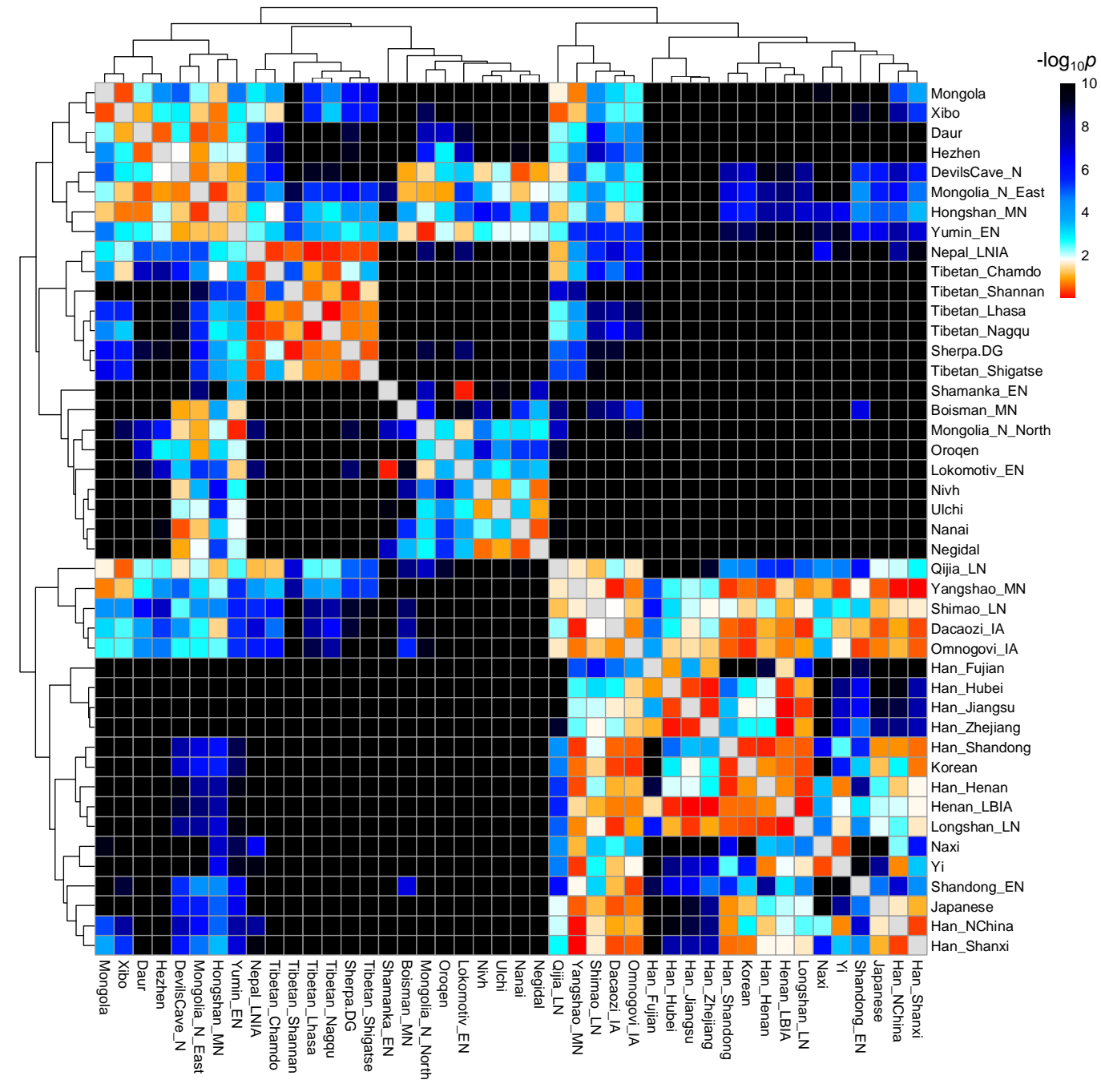


Figure 5. Illustrations for demographic history in East Asia. (A) The formation of geographically and linguistically structured ancestries in East Asia. (B) Massive migrations and admixtures forming the current genomic landscape in Southern China and neighboring regions.

A

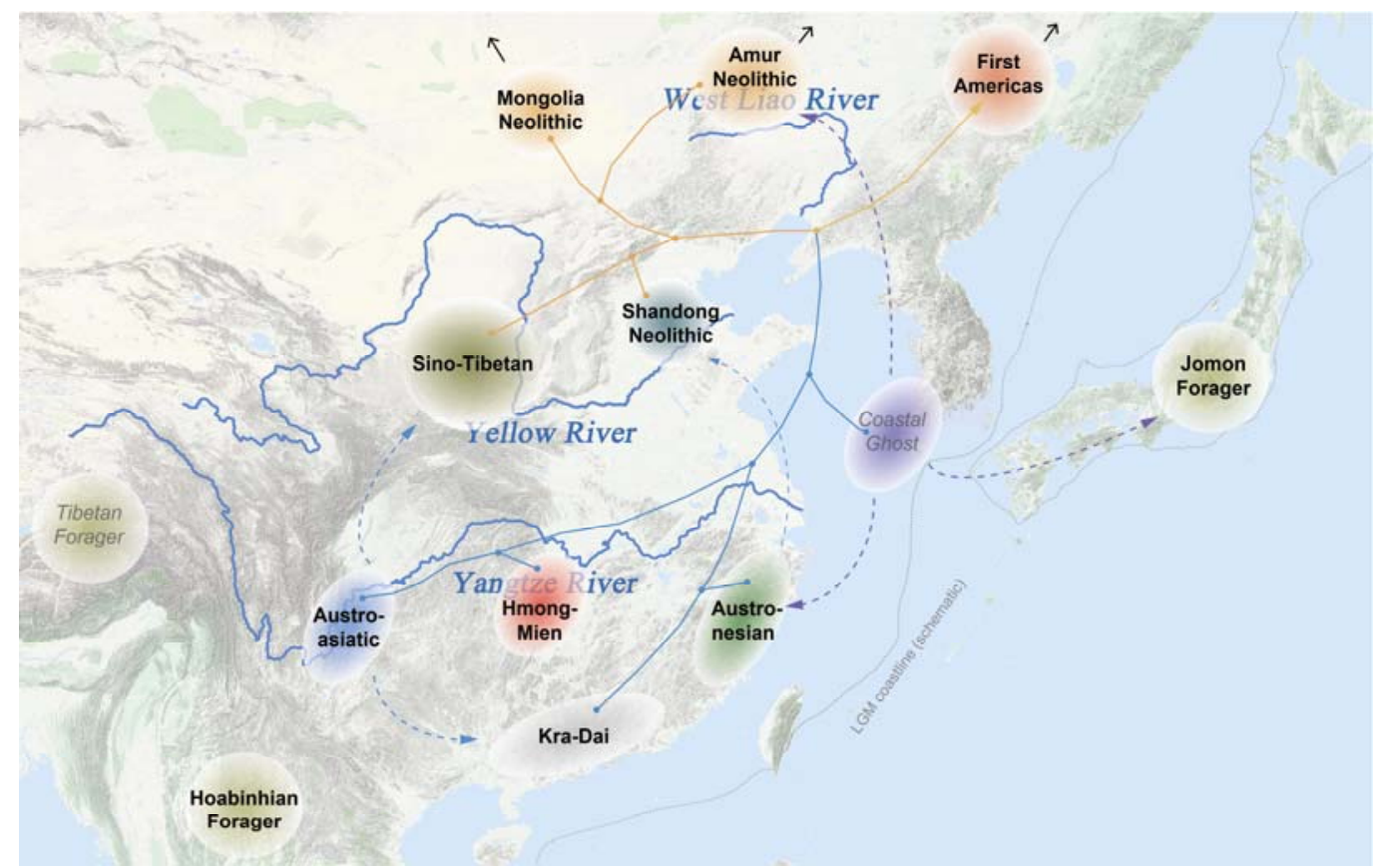

B

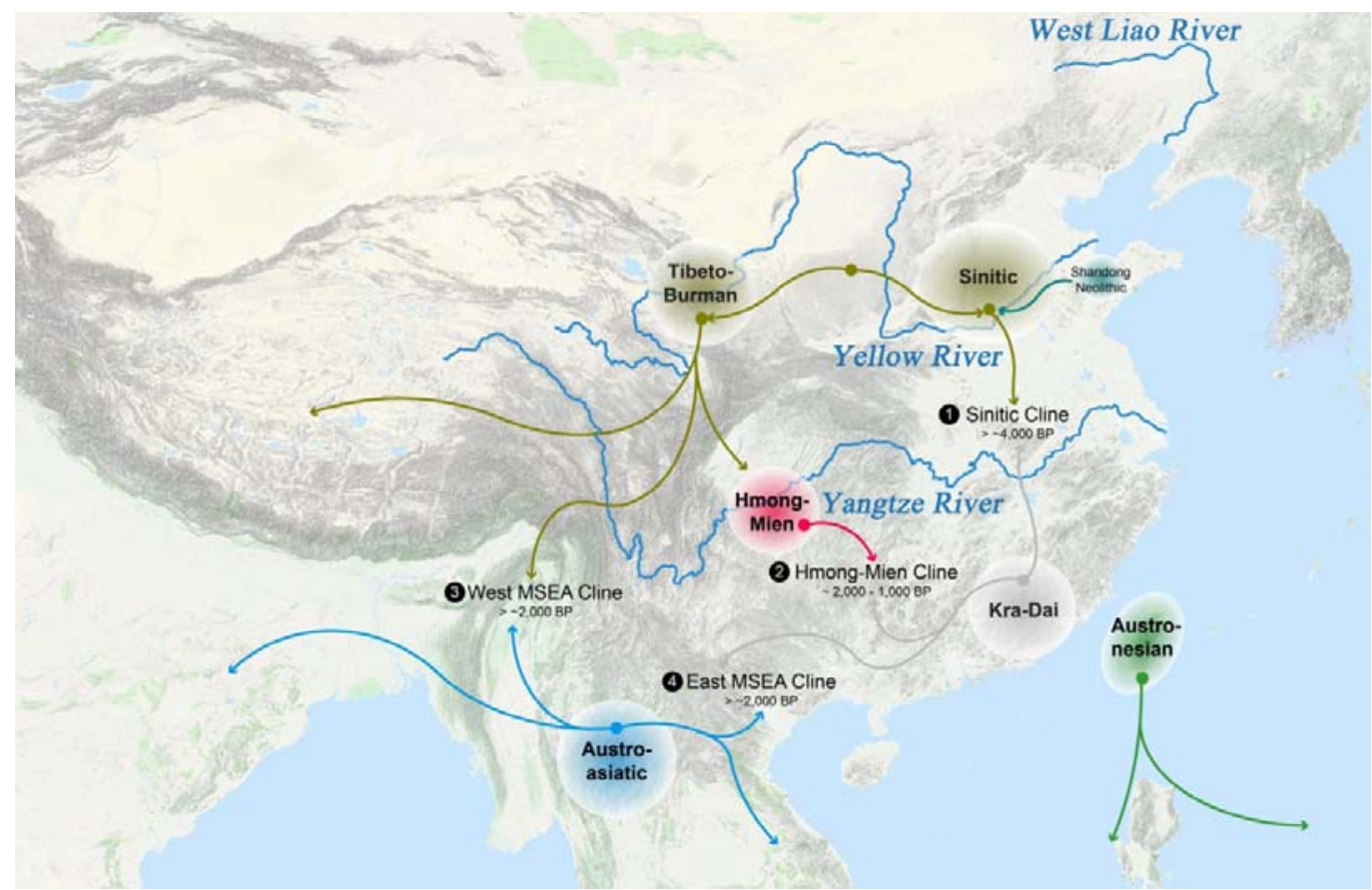




\section{Extended Data Figure 1. Correlation between effective population size $\left(\mathrm{N}_{\mathrm{E}}\right)$ and genetic drift away from common Eurasian ancestor. Given $\sim 45,000$ years old} Ust'-Ishim is genomically equally related to most of the Eurasians, we used $\mathrm{F}_{\mathrm{ST}}$ away from him $\left[\mathrm{F}_{\mathrm{ST}}(\mathrm{X}, \mathrm{Ust}\right.$ '-Ishim)] to represent the genetic drift from the common Eurasian ancestor to modern East Asian populations. Negative correlation between logarithm of $\mathrm{N}_{\mathrm{E}}$ and $\mathrm{F}_{\mathrm{ST}}(\mathrm{X}$, Ust'-Ishim) suggests that recent genetic drift due to a small population size comprise a large proportion of the total genetic drift from common Eurasian ancestor in many modern East Asian populations.

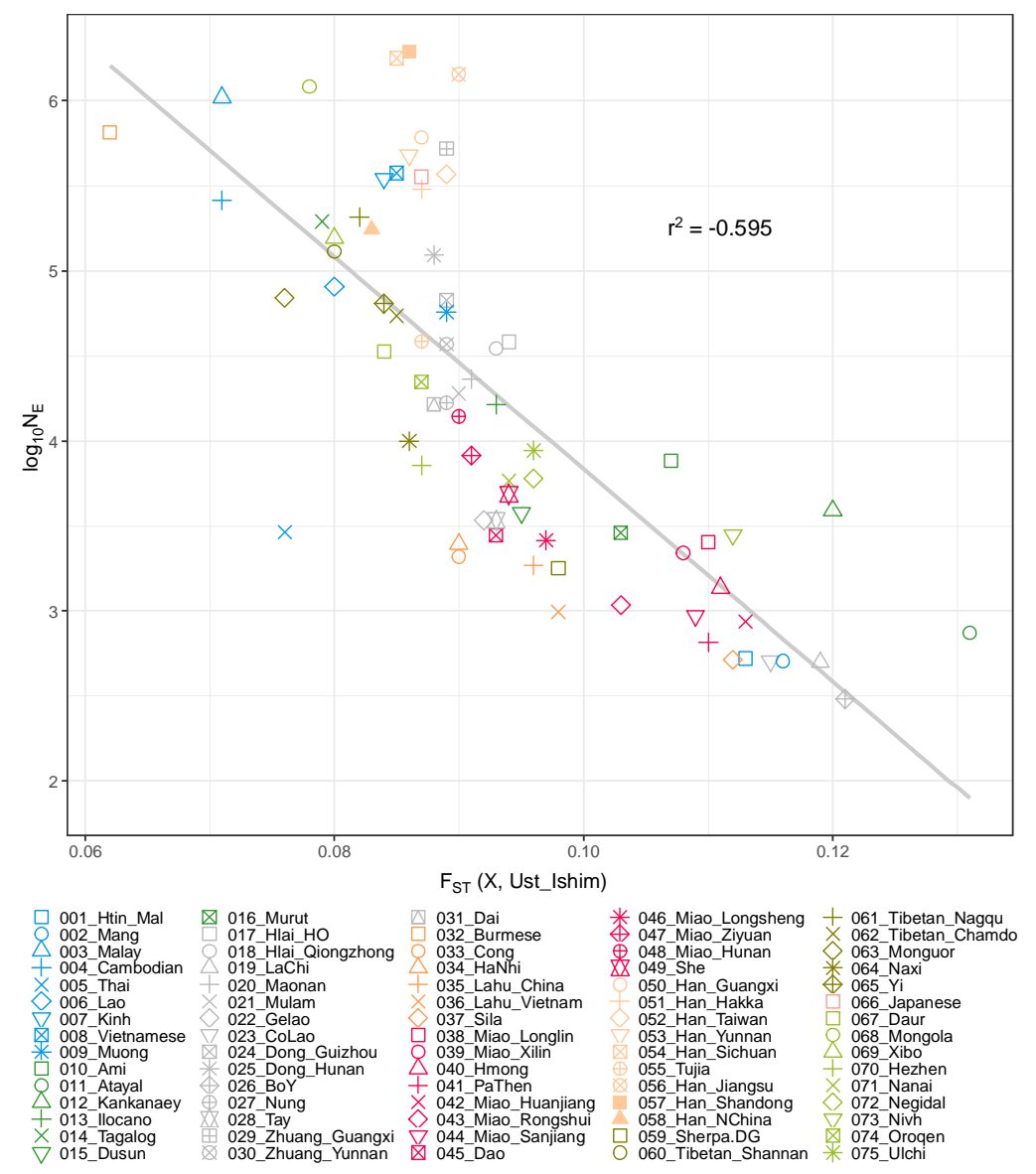


bioRxiv preprint doi: https://doi.org/10.1101/2020.11.08.373225; this version posted November 8, 2020. The copyright holder for this preprint (which was not certified by peer review) is the author/funder, who has granted bioRxiv a license to display the preprint in perpetuity. It is made available under aCC-BY-NC 4.0 International license.

Extended Data Figure 2. Cross error for ADMIXTURE analysis when $\mathrm{K}=\mathbf{2}$ to 20.

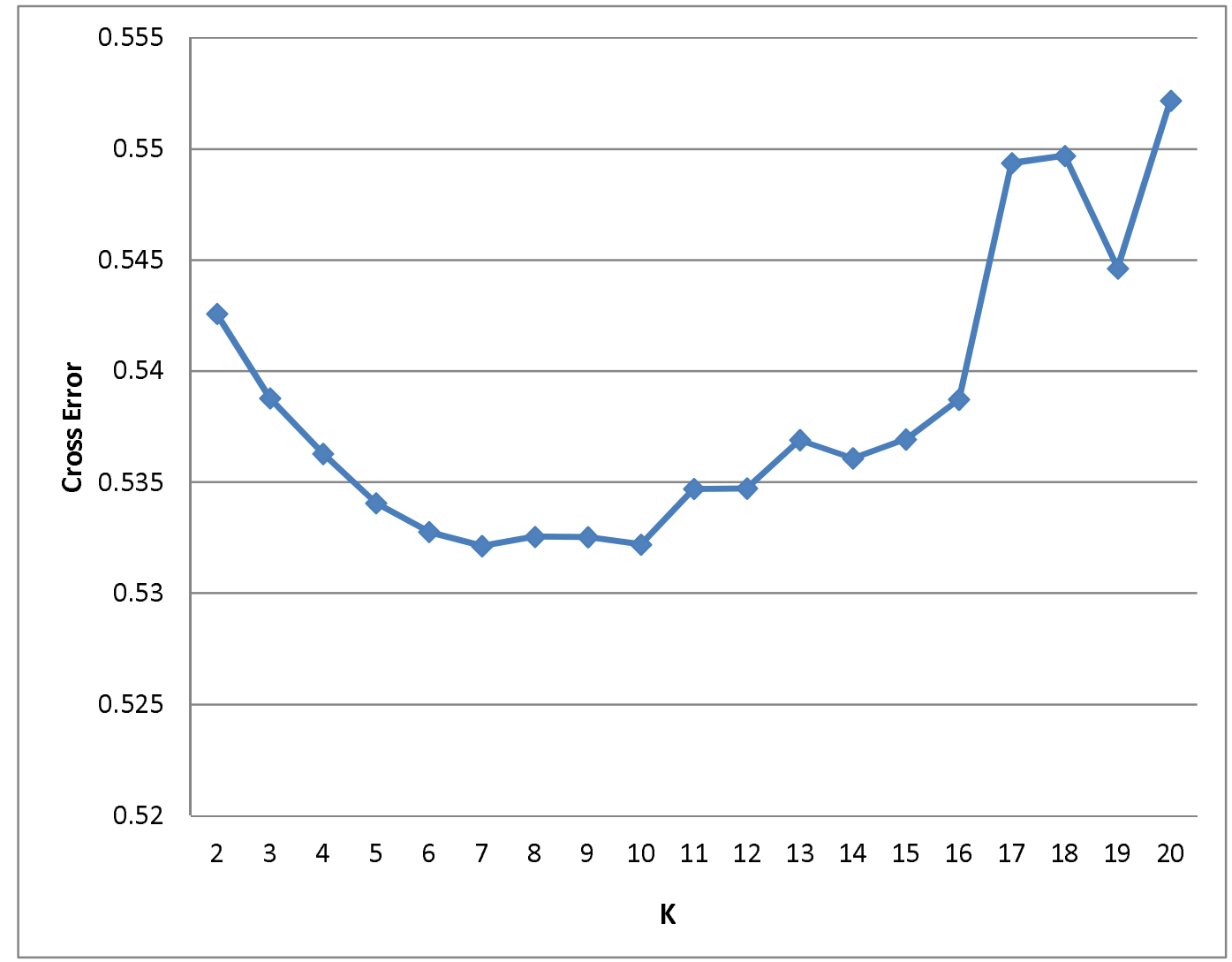


bioRxiv preprint doi: https://doi.org/10.1101/202011.08.373225; this version posted November 8,2020 . The copyright holder for this preprint (which was not certified by peer review) is the author/funder, who has granted bioRxiv a license to display the preprint in perpetuity. It is made available under aCC-BY-NC 4.0 International license.

Extended Data Table 1. Sample information for newly reported individuals in this study.

\begin{tabular}{|c|c|c|c|c|c|c|c|}
\hline Population & Language Affiliation & Locality & Region & Latitude & Longitude & Grouped label & Sample size \\
\hline Miao_Longlin & HM, Hmongic, Hmong & Longlin, Baise, Guangxi & China (Southwest) & 24.7714 & 105.3456 & Miao_Longlin & 10 \\
\hline Miao_Xilin & HM, Hmongic, Hmong & Xilin, Baise, Guangxi & China (Southwest) & 24.4924 & 105.0929 & Miao_Xilin & 10 \\
\hline Miao_Huanjiang & HM, Hmongic, Hmu, Southern Dialect & Huanjiang, Hechi, Guangxi & China (Southwest) & 24.8363 & 108.2538 & Miao_Huanjiang & 8 \\
\hline Miao_Rongshui & HM, Hmongic, Hmu, Southern Dialect & Rongshui, Liuzhou, Guangxi & China (Southwest) & 25.0748 & 109.2537 & Miao_Rongshui & 10 \\
\hline Miao_Sanjiang & HM, Hmongic, Hmu, Southern Dialect & Sanjiang, Liuzhou, Guangxi & China (Southwest) & 25.7818 & 109.6064 & Miao_Sanjiang & 9 \\
\hline Miao_Ziyuan & HM, Hmongic, Hmu, Eastern Dialect & Ziyuan, Guilin, Guangxi & China (Southwest) & 26.0365 & 110.6397 & Miao_Ziyuan & 10 \\
\hline Miao_Longsheng & HM, Hmongic, Hmu, Eastern Dialect & Longsheng, Guilin, Guangxi & China (Southwest) & 25.7992 & 110.0081 & Miao_Longsheng & 10 \\
\hline Zhuang_Qiubei & KD, Tai, Northern Tai & Quibei, Wenshan, Yunnan & China (Southwest) & 24.0428 & 104.1887 & Zhuang_Yunnan & 9 \\
\hline Zhuang_Guangnan & KD, Tai, Central Tai & Guangnan, Wenshan, Yunnan & China (Southwest) & 24.0458 & 105.0535 & Zhuang_Yunnan & 5 \\
\hline Zhuang_Wenshan & KD, Tai, Central Tai & Wenshan, Wenshan, Yunnan & China (Southwest) & 23.3864 & 104.2318 & Zhuang_Yunnan & 10 \\
\hline Zhuang_Tianlin & KD, Tai, Northern Tai & Tianlin, Baise, Guangxi & China (Southwest) & 24.2946 & 106.2306 & Zhuang_Guangxi & 10 \\
\hline Zhuang_Tianyang & KD, Tai, Northern Tai & Tianyang, Baise, Guangxi & China (Southwest) & 23.7377 & 106.9160 & Zhuang_Guangxi & 6 \\
\hline Zhuang_Jingxi & KD, Tai, Central Tai & Jingxi, Baise, Guangxi & China (Southwest) & 23.1355 & 106.4171 & Zhuang_Guangxi & 9 \\
\hline Zhuang_Chongzuo & KD, Tai, Central Tai & Jiangzhou, Chongzuo, Guangxi & China (Southwest) & 22.4071 & 107.3546 & Zhuang_Guangxi & 10 \\
\hline Zhuang_Fusui & KD, Tai, Central Tai & Fusui, Chongzuo, Guangxi & China (Southwest) & 22.6350 & 107.9041 & Zhuang_Guangxi & 6 \\
\hline Zhuang_Wuming & KD, Tai, Central Tai & Wuming, Nanning, Guangxi & China (Southwest) & 23.1560 & 108.2841 & Zhuang_Guangxi & 1 \\
\hline Zhuang_Hechi & KD, Tai, Northern Tai & Jinchengjiang, Hechi, Guangxi & China (Southwest) & 24.6944 & 108.0846 & Zhuang_Guangxi & 9 \\
\hline Zhuang_Guigang & KD, Tai, Northern Tai & Gangnan, Guigang, Guangxi & China (Southwest) & 23.1107 & 109.5978 & Zhuang_Guangxi & 10 \\
\hline Zhuang_Laibin & KD, Tai, Northern Tai & Xingbin, Laibin, Guangxi & China (Southwest) & 23.7402 & 109.1962 & Zhuang_Guangxi & 6 \\
\hline Han_Qiubei & ST, Sinitic, SW Mandarin, Diannan & Quibei, Wenshan, Yunnan & China (Southwest) & 24.0428 & 104.1887 & Han_Yunnan & 6 \\
\hline Han_Guangnan & ST, Sinitic, SW Mandarin, Diannan & Guangnan, Wenshan, Yunnan & China (Southwest) & 24.0458 & 105.0535 & Han_Yunnan & 3 \\
\hline Han_Wenshan & ST, Sinitic, SW Mandarin, Diannan & Wenshan, Wenshan, Yunnan & China (Southwest) & 23.3864 & 104.2318 & Han_Yunnan & 7 \\
\hline Han_Tianlin & ST, Sinitic, Pinghua & Tianlin, Baise, Guangxi & China (Southwest) & 24.2946 & 106.2306 & Han_Guangxi & 5 \\
\hline Han_Tianyang & ST, Sinitic, Pinghua & Tianyang, Baise, Guangxi & China (Southwest) & 23.7377 & 106.9160 & Han_Guangxi & 5 \\
\hline Han_Jingxi & ST, Sinitic, SW Mandarin, Guiliu & Jingxi, Baise, Guangxi & China (Southwest) & 23.1355 & 106.4171 & Han_Guangxi & 5 \\
\hline Han_Chongzuo & ST, Sinitic, Pinghua & Jiangzhou, Chongzuo, Guangxi & China (Southwest) & 22.4071 & 107.3546 & Han_Guangxi & 5 \\
\hline Han_Fusui & ST, Sinitic, Pinghua & Fusui, Chongzuo, Guangxi & China (Southwest) & 22.6350 & 107.9041 & Han_Guangxi & 1 \\
\hline Han_Hechi & ST, Sinitic, SW Mandarin, Guiliu & Jinchengjiang, Hechi, Guangxi & China (Southwest) & 24.6944 & 108.0846 & Han_Guangxi & 6 \\
\hline Han_Guigang & ST, Sinitic, Pinghua & Gangnan, Guigang, Guangxi & China (Southwest) & 23.1107 & 109.5978 & Han_Guangxi & 6 \\
\hline Han_Laibin & ST, Sinitic, SW Mandarin, Guiliu & Xingbin, Laibin, Guangxi & China (Southwest) & 23.7402 & 109.1962 & Han_Guangxi & 4 \\
\hline
\end{tabular}




\section{Extended Data Table 2. Correlation between the proportion of ancestries and}

corresponding language families. We used point-biserial correlation to quantify if an individual affiliated to a certain language family tends to have more proportion of the ancestry corresponding to this language family. We further used the $p$-value of student's t-test to quantify if the correlation is significant. $r_{\mathrm{pb}}$, point-biserial correlation coefficient.

\begin{tabular}{lcc}
\hline Language Families & $\mathbf{r}_{\mathbf{p b}}$ & $\boldsymbol{p}$-value \\
\hline Hmong-Mien & 0.762 & $2.13 \times 10^{-31}$ \\
Kra-Dai & 0.644 & $9.77 \times 10^{-189}$ \\
Austroasiatic & 0.536 & $6.73 \times 10^{-12}$ \\
Austronesian & 0.921 & $7.23 \times 10^{-32}$ \\
Sino-Tibetan & 0.630 & $4.81 \times 10^{-83}$ \\
Tungusic/ Amuric & 0.806 & $7.34 \times 10^{-31}$ \\
\hline
\end{tabular}


bioRxiv preprint doi: https://doi.org/10.1101/2020.11.08.373225; this version posted November 8,2020 . The copyright holder for this preprint (which was not certified by peer review) is the author/funder, who has granted bioRxiv a license to display the preprint in perpetuity. It is made available under aCC-BY-NC 4.0 International license.

Extended Data Table 3. Admixture- $f_{3}$ results. (A) Tibeto-Burman populations. (B) Southeast Han Chinese. (C) Kra-Dai and Vietic populations. We report the five lowest $f_{3}$ results for each of the populations. std.err, standard error.

A

\begin{tabular}{|c|c|c|c|c|c|c|}
\hline Source_1 & Source_2 & Target & f_3 & std.err & $\mathbf{Z}$ & SNPs \\
\hline Mekong_N & Yumin_EN & Naxi & -0.001575 & 0.002227 & -0.708 & 69321 \\
\hline Mlabri & Tibetan_Chamdo & Naxi & -0.001207 & 0.000555 & -2.177 & 105215 \\
\hline Mekong_N & Sherpa.DG & Naxi & -0.001042 & 0.001291 & -0.807 & 83146 \\
\hline Mekong_N & Tibetan_Chamdo & Naxi & -0.001036 & 0.00068 & -1.523 & 87697 \\
\hline Mekong_N & Tibetan_Nagqu & Naxi & -0.000908 & 0.000777 & -1.17 & 87061 \\
\hline Mlabri & Tibetan_Chamdo & $\mathrm{Yi}$ & -0.00375 & 0.000573 & -6.544 & 105393 \\
\hline Malaysia_LN.SG & Yumin_EN & Yi & -0.003742 & 0.002493 & -1.501 & 67896 \\
\hline Mekong_N & Yumin_EN & Yi & -0.003681 & 0.002139 & -1.721 & 70135 \\
\hline Ami & Tibetan_Chamdo & Yi & -0.00366 & 0.000363 & -10.085 & 106865 \\
\hline Malaysia_LN.SG & Tibetan_Chamdo & $\mathrm{Yi}$ & -0.003537 & 0.000795 & -4.451 & 84607 \\
\hline Mekong_N & Yumin_EN & Sila & 0.029056 & 0.002478 & 11.724 & 67679 \\
\hline Mekong_N & Qijia_LN & Sila & 0.030261 & 0.001622 & 18.661 & 81896 \\
\hline Malaysia_LN.SG & Qijia_LN & Sila & 0.03054 & 0.001782 & 17.139 & 78608 \\
\hline Mlabri & Tibetan_Chamdo & Sila & 0.03056 & 0.000988 & 30.924 & 104727 \\
\hline Mekong_N & Tibetan_Chamdo & Sila & 0.030608 & 0.001149 & 26.649 & 87209 \\
\hline Mekong_N & Yumin_EN & HaNhi & 0.00217 & 0.002201 & 0.986 & 69776 \\
\hline Mlabri & Tibetan_Chamdo & HaNhi & 0.003446 & 0.000648 & 5.317 & 105256 \\
\hline Mekong_N & Tibetan_Nagqu & HaNhi & 0.003451 & 0.000859 & 4.018 & 87152 \\
\hline Mlabri & Lokomotiv_EN & HaNhi & 0.003579 & 0.001226 & 2.919 & 89625 \\
\hline Mekong_N & Qijia_LN & HaNhi & 0.00363 & 0.001297 & 2.799 & 83933 \\
\hline Mekong_N & Yumin_EN & Cong & 0.003042 & 0.002203 & 1.381 & 69905 \\
\hline Malaysia_LN.SG & Qijia_LN & Cong & 0.00389 & 0.001518 & 2.563 & 80814 \\
\hline Mekong_N & Sherpa.DG & Cong & 0.004221 & 0.00135 & 3.127 & 83654 \\
\hline Mekong_N & Qijia_LN & Cong & 0.004291 & 0.001311 & 3.274 & 84076 \\
\hline Malaysia_LN.SG & Yumin_EN & Cong & 0.004553 & 0.002551 & 1.785 & 67698 \\
\hline Mekong_N & Yumin_EN & Lahu_China & 0.009174 & 0.002329 & 3.94 & 67477 \\
\hline Malaysia_LN.SG & Yumin_EN & Lahu_China & 0.010163 & 0.002762 & 3.68 & 65140 \\
\hline Malaysia_LN.SG & Qijia_LN & Lahu_China & 0.010199 & 0.001622 & 6.286 & 78604 \\
\hline Malaysia_LN.SG & Tibetan_Chamdo & Lahu_China & 0.010683 & 0.001132 & 9.437 & 84250 \\
\hline Mekong_N & Sherpa.DG & Lahu_China & 0.010862 & 0.001495 & 7.267 & 81702 \\
\hline Mekong_N & Yumin_EN & Lahu_Vietnam & 0.008825 & 0.00227 & 3.889 & 68785 \\
\hline Malaysia_LN.SG & Yumin_EN & Lahu_Vietnam & 0.010852 & 0.002663 & 4.074 & 66561 \\
\hline Mekong_N & Qijia_LN & Lahu_Vietnam & 0.012234 & 0.001375 & 8.895 & 82996 \\
\hline Mlabri & Yumin_EN & Lahu_Vietnam & 0.012279 & 0.001718 & 7.146 & 84001 \\
\hline Malaysia_LN.SG & Qijia_LN & Lahu_Vietnam & 0.012334 & 0.001543 & 7.994 & 79719 \\
\hline
\end{tabular}


bioRxiv preprint doi: https://doi.org/10.1101/2020.11.08.373225; this version posted November 8,2020 . The copyright holder for this preprint (which was not certified by peer review) is the author/funder, who has granted bioRxiv a license to display the preprint in perpetuity. It is made available under aCC-BY-NC 4.0 International license.

B

\begin{tabular}{|c|c|c|c|c|c|c|}
\hline Source_1 & Source_2 & Target & f_3 & std.err & $\mathbf{Z}$ & SNPs \\
\hline$\overline{\text { Atayal }}$ & Qijia_LN & Han_Fujian & -0.005661 & 0.000819 & -6.912 & 100135 \\
\hline Kankanaey & Qijia_LN & Han_Fujian & -0.004939 & 0.000759 & -6.506 & 100676 \\
\hline Atayal & Yumin EN & Han Fujian & -0.004855 & 0.00132 & -3.68 & 83301 \\
\hline Hlai Qiongzhong & Qijia $\overline{L N}$ & Han Fujian & -0.004405 & 0.000645 & -6.828 & 105279 \\
\hline Kankanaey & Yangshao_MN & Han_Fujian & -0.004354 & 0.000834 & -5.222 & 100270 \\
\hline Atayal & Yumin_EN & Han_Guangdong & -0.005255 & 0.001198 & -4.385 & 84603 \\
\hline Hlai_Qiongzhong & Yumin_EN & Han_Guangdong & -0.004742 & 0.000835 & -5.677 & 88521 \\
\hline Atayal & Qijia_LN & Han_Guangdong & -0.004456 & 0.000746 & -5.97 & 101411 \\
\hline Ami & Yumin_EN & Han_Guangdong & -0.004278 & 0.001073 & -3.989 & 85412 \\
\hline Maonan & Yumin_EN & Han_Guangdong & -0.004173 & 0.000876 & -4.762 & 87806 \\
\hline Atayal & Qijia LN & Han Taiwan & -0.004181 & 0.000711 & -5.882 & 101169 \\
\hline Atayal & Yumin_EN & Han_Taiwan & -0.004013 & 0.001229 & -3.266 & 84541 \\
\hline Hlai_Qiongzhong & Yumin_EN & Han_Taiwan & -0.003404 & 0.000833 & -4.084 & 88057 \\
\hline Kankanaey & Qijia_L̄N & Han_Taiwan & -0.00315 & 0.000651 & -4.836 & 101443 \\
\hline Hlai_Qiongzhong & Qijia_LN & Han_Taiwan & -0.003081 & 0.000511 & -6.034 & 104904 \\
\hline Qijia_LN & Atayal & Han_Hakka & -0.005343 & 0.000696 & -7.673 & 101131 \\
\hline Qijia_LN & Kankanaey & Han_Hakka & -0.004676 & 0.000635 & -7.367 & 101487 \\
\hline Sherpa.DG & Kankanaey & Han_Hakka & -0.004664 & 0.000734 & -6.351 & 100941 \\
\hline Tibetan Chamdo & Ami & Han Hakka & -0.004617 & 0.000436 & -10.584 & 105655 \\
\hline Sherpa.DG & Ami & Han_Hakka & -0.004606 & 0.00068 & -6.774 & 101421 \\
\hline Mongolia_N_North & Hlai_HO & Han_Guangxi & -0.004074 & 0.000537 & -7.583 & 103164 \\
\hline Qijia_LN & Atayal & Han_Guangxi & -0.004072 & 0.00054 & -7.54 & 107035 \\
\hline Yumin_EN & Atayal & Han_Guangxi & -0.003639 & 0.000981 & -3.71 & 89909 \\
\hline Qijia_LN & Hlai_HO & Han_Guangxi & -0.003628 & 0.000494 & -7.344 & 106925 \\
\hline Qijia_LN & Hlai_Qiongzhong & Han_Guangxi & -0.003512 & 0.00029 & -12.119 & 107881 \\
\hline Atayal & Qijia_LN & Han_Zhejiang & -0.005071 & 0.000843 & -6.015 & 100136 \\
\hline Kankanaey & Qijia_LN & Han_Zhejiang & -0.004388 & 0.0008 & -5.486 & 100775 \\
\hline Ami & Qijia_LN & Han_Zhejiang & -0.004223 & 0.000729 & -5.797 & 101373 \\
\hline Hlai_HO & Qijia_LN & Han_Zhejiang & -0.004132 & 0.000812 & -5.089 & 99336 \\
\hline Hlai_HO & Boisman_MN & Han_Zhejiang & -0.003947 & 0.000837 & -4.717 & 93260 \\
\hline Atayal & Qijia_LN & CHS.SG & -0.0021 & 0.000535 & -3.927 & 107824 \\
\hline Kankanaey & Qijia_LN & CHS.SG & -0.0013 & 0.000469 & -2.774 & 107480 \\
\hline Ami & Qijia_LN & CHS.SG & -0.000939 & 0.000421 & -2.23 & 107882 \\
\hline Hlai_Qiongzhong & Qijia_LN & CHS.SG & -0.00088 & 0.0003 & -2.936 & 108513 \\
\hline Hlai_HO & Qijia_LN & CHS.SG & -0.000867 & 0.000481 & -1.802 & 107768 \\
\hline
\end{tabular}


bioRxiv preprint doi: https://doi.org/10.1101/2020.11.08.373225; this version posted November 8, 2020. The copyright holder for this preprint

(which was not certified by peer review) is the author/funder, who has granted bioRxiv a license to display the preprint in perpetuity. It is made available under aCC-BY-NC 4.0 International license.

C

\begin{tabular}{|c|c|c|c|c|c|c|}
\hline Source_1 & Source_2 & Target & f_3 & std.err & $\mathbf{Z}$ & SNPS \\
\hline Mlabri & Fujian_LN & Hlai_Qiongzhong & 0.001787 & 0.0011920 & 1.499 & 69995 \\
\hline Mekong_N & Ami & Hlai_Qiongzhong & 0.002454 & 0.0007040 & 3.485 & 87834 \\
\hline Mekong_N & Atayal & Hlai_Qiongzhong & 0.003009 & 0.0008930 & 3.370 & 87595 \\
\hline Malaysia_LN.SG & Ami & Hlai_Qiongzhong & 0.003022 & 0.0008760 & 3.449 & 84545 \\
\hline Mekong_ $\bar{N}$ & Kankanaey & Hlai_Qiongzhong & 0.003176 & 0.0008100 & 3.920 & 87457 \\
\hline Mlabri & Fujian_LN & Zhuang_Guangxi & -0.002579 & 0.0011180 & -2.306 & 72220 \\
\hline Hlai_HO & Mongolia_N_North & Zhuang_Guangxi & -0.002157 & 0.0005480 & -3.934 & 104259 \\
\hline Mekong_N & Ami & Zhuang_Guangxi & -0.002070 & 0.0006260 & -3.309 & 90401 \\
\hline Hlai_HO & Kolyma_M & Zhuang_Guangxi & -0.001675 & 0.0008670 & -1.932 & 108675 \\
\hline Mekong_N & Atayal & Zhuang_Guangxi & -0.001607 & 0.0008380 & -1.917 & 90347 \\
\hline Mlabri & Fujian_LN & Zhuang_Yunnan & -0.002457 & 0.001131 & -2.172 & 70278 \\
\hline Mlabri & Qine_EN & Zhuang_Yunnan & -0.00186 & 0.001865 & -0.998 & 38807 \\
\hline Mlabri & Kankanaey & Zhuang_Yunnan & -0.001246 & 0.000609 & -2.045 & 105224 \\
\hline Mekong_N & Atayal & Zhuang_Yunnan & -0.001242 & 0.00091 & -1.365 & 88055 \\
\hline Mekong_N & Ami & Zhuang_Yunnan & -0.001209 & 0.000707 & -1.709 & 88247 \\
\hline Mlabri & Fujian_LN & CDX.SG & -0.00053 & 0.001087 & -0.487 & 72015 \\
\hline Mlabri & Qine_EN & CDX.SG & -0.000412 & 0.001793 & -0.23 & 39820 \\
\hline Mlabri & Liangdao1_EN & CDX.SG & 0.000201 & 0.001681 & 0.119 & 56649 \\
\hline Mekong_N & Ami & CDX.SG & 0.00031 & 0.000664 & 0.466 & 90185 \\
\hline Mekong_N & Hezhen & CDX.SG & 0.000581 & 0.000696 & 0.835 & 90781 \\
\hline Hlai_HO & Kolyma_M & Mulam & -0.000988 & 0.000961 & -1.028 & 104445 \\
\hline Hlai_HO & Mongolia_N_North & Mulam & -0.000853 & 0.000629 & -1.356 & 100764 \\
\hline Fujian_LN & Mlabri & Mulam & -0.000814 & 0.001178 & -0.692 & 69313 \\
\hline Hlai $\mathrm{HO}$ & Qijia LN & Mulam & -0.000519 & 0.000571 & -0.909 & 104153 \\
\hline Hlai_Qiongzhong & Qijia_LN & Mulam & -0.000489 & 0.000364 & -1.343 & 106533 \\
\hline Mlabri & Fujian_LN & Dai & -0.001628 & 0.001278 & -1.273 & 67817 \\
\hline Mekong_N & Atayal & Dai & -0.001387 & 0.000958 & -1.447 & 85437 \\
\hline Mekong_N & Ami & Dai & -0.001195 & 0.000813 & -1.47 & 86033 \\
\hline Mlabri & Liangdao1_EN & Dai & -0.001099 & 0.001813 & -0.606 & 53082 \\
\hline Mekong_N & Kankanaey & Dai & -0.000769 & 0.000895 & -0.858 & 85539 \\
\hline Qihe_EN & Mlabri & Maonan & -0.000708 & 0.001897 & -0.373 & 38205 \\
\hline Fujian_LN & Mlabri & Maonan & -0.000669 & 0.001211 & -0.553 & 69171 \\
\hline Hlai_HO & Kolyma_M & Maonan & -0.000049 & 0.000991 & -0.05 & 104275 \\
\hline Qihe_EN & Miao_Longlin & Maonan & 0.000224 & 0.0012 & 0.187 & 38806 \\
\hline Ami & Mekong_N & Maonan & 0.000309 & 0.000745 & 0.414 & 87016 \\
\hline Miao_Longlin & Qihe_EN & CoLao & 0.026857 & 0.001809 & 14.85 & 37582 \\
\hline Miao_Longlin & Liangdao1_EN & CoLao & 0.02686 & 0.001497 & 17.938 & 53446 \\
\hline Miao_Xilin & Malaysia_LNN.SG & CoLao & 0.027253 & 0.001376 & 19.812 & 81187 \\
\hline Miao_Longlin & Mekong_ $\bar{N}$ & CoLao & 0.02745 & 0.001196 & 22.945 & 84419 \\
\hline Yumin_EN & Mekong_N & CoLao & 0.027586 & 0.002572 & 10.727 & 66989 \\
\hline Mlabri & Qine_EN & Gelao & 0.000421 & 0.001948 & 0.216 & 37203 \\
\hline Mlabri & Fujian_LN & Gelao & 0.00056 & 0.001252 & 0.447 & 67550 \\
\hline Mlabri & Longshan_LN & Gelao & 0.001273 & 0.000756 & 1.683 & 102065 \\
\hline Mlabri & Yangshao_MN & Gelao & 0.001494 & 0.001025 & 1.457 & 100619 \\
\hline Mlabri & Liangdao1_EN & Gelao & 0.001592 & 0.001851 & 0.86 & 52851 \\
\hline Mlabri & Fujian_LN & LaChi & 0.033654 & 0.00162 & 20.769 & 66235 \\
\hline Malaysia_LN.SG & Qijia_LN & LaChi & 0.034132 & 0.001792 & 19.042 & 78138 \\
\hline Mekong_ $\bar{N}$ & Ami & LaChi & 0.034462 & 0.001275 & 27.033 & 84541 \\
\hline Malaysia_LN.SG & Yumin_EN & LaChi & 0.034524 & 0.002895 & 11.925 & 64779 \\
\hline Mlabri & Qine_EN & LaChi & 0.034846 & 0.002477 & 14.07 & 36410 \\
\hline Malaysia_LN.SG & Yumin_EN & Kinh & -0.005497 & 0.002521 & -2.18 & 66590 \\
\hline Mekong_ $\bar{N}$ & Yumin_EN & Kinh & -0.004957 & 0.002151 & -2.304 & 68862 \\
\hline Mlabri & Fujian_LN & Kinh & -0.00494 & 0.001269 & -3.892 & 67451 \\
\hline Malaysia_LN.SG & Qijia_LN & Kinh & -0.004437 & 0.001486 & -2.985 & 80021 \\
\hline Mlabri & Yangshao_MN & Kinh & -0.004388 & 0.001001 & -4.382 & 100543 \\
\hline Mlabri & Qine_EN & Muong & -0.003278 & 0.001942 & -1.688 & 37341 \\
\hline Mlabri & Fujian_LN & Muong & -0.002737 & 0.001205 & -2.273 & 67833 \\
\hline Mekong_N & Ami & Muong & -0.002661 & 0.000843 & -3.158 & 85867 \\
\hline Mekong_N & Kankanaey & Muong & -0.00232 & 0.000908 & -2.553 & 85724 \\
\hline Mekong_N & Atayal & Muong & -0.002275 & 0.000966 & -2.354 & 85258 \\
\hline Mekong_N & Hezhen & KHV.SG & -0.001114 & 0.000653 & -1.705 & 91653 \\
\hline Mekong_N & Yumin_EN & KHV.SG & -0.001059 & 0.002048 & -0.517 & 75980 \\
\hline Malaysia_LN.SG & Qijia_LN & KHV.SG & -0.001 & 0.001286 & -0.778 & 87386 \\
\hline Mlabri & Qine_EN & KHV.SG & -0.000881 & 0.001796 & -0.491 & 40278 \\
\hline Mlabri & Fujian_LN & KHV.SG & -0.000864 & 0.001083 & -0.798 & 72809 \\
\hline Mekong_N & Ami & Nung & -0.001796 & 0.000768 & -2.339 & 85969 \\
\hline Mekong_N & Atayal & Nung & -0.00178 & 0.000917 & -1.941 & 85459 \\
\hline Mlabri & Fujian_LN & Nung & -0.001548 & 0.00118 & -1.311 & 68167 \\
\hline Mekong_N & Hezhen & Nung & -0.001542 & 0.000792 & -1.946 & 87392 \\
\hline Mlabri & Qine_EN & Nung & -0.001188 & 0.001907 & -0.623 & 37606 \\
\hline Mlabri & Qihe EN & Lao & -0.006126 & 0.001913 & -3.203 & 37733 \\
\hline Mlabri & Fujian LN & Lao & -0.006086 & 0.00118 & -5.158 & 68494 \\
\hline Mekong_N & Ami & Lao & -0.005638 & 0.000799 & -7.057 & 86114 \\
\hline Mlabri & Liangdao1_EN & Lao & -0.005427 & 0.001802 & -3.012 & 53597 \\
\hline Mekong_N & Hezhen & Lao & -0.005185 & 0.000809 & -6.41 & 87452 \\
\hline
\end{tabular}


bioRxiv preprint doi: https://doi.org/10.1101/2020.11.08.373225; this version posted November 8,2020 . The copyright holder for this preprint (which was not certified by peer review) is the author/funder, who has granted bioRxiv a license to display the preprint in perpetuity. It is made available under aCC-BY-NC 4.0 International license.

\section{Extended Data Table 4. Admixture time estimates for Hmong-Mien Cline inferred by ALDER.}

\begin{tabular}{|c|c|c|c|c|c|}
\hline$p$-value & target & reference A & reference B & Z-score & $\begin{array}{c}\text { admixture time } \\
\text { estimate }\end{array}$ \\
\hline $1.5 \mathrm{E}-10$ & Miao_Rongshui & Hmong_Core & CHB.SG & 6.40 & $24.43 \pm 3.82$ \\
\hline 1.6E-07 & Miao_Sanjiang & Hmong_Core & Austronesian_Core & 5.25 & $25.80 \pm 4.92$ \\
\hline 6.8E-09 & Miao_Rongshui & Hmong_Core & KHV.SG & 5.80 & $25.92 \pm 4.47$ \\
\hline $1.8 \mathrm{E}-13$ & Miao_Rongshui & Hmong_Core & CDX.SG & 7.36 & $26.76 \pm 3.64$ \\
\hline 4.4E-10 & Miao_Sanjiang & Hmong_Core & Tibetan_Core & 6.24 & $26.86 \pm 4.30$ \\
\hline 4.8E-07 & Dong_Hunan & Hmong_Core & Hlai_all & 5.03 & $26.97 \pm 5.36$ \\
\hline 5.4E-09 & Miao_Rongshui & Hmong_Core & Amur_Core & 5.83 & $27.02 \pm 4.63$ \\
\hline 2.9E-09 & Miao_Sanjiang & Hmong_Core & CHS.SG & 5.93 & $27.08 \pm 4.56$ \\
\hline 2.9E-09 & Miao_Sanjiang & Hmong_Core & CHS.SG & 5.93 & $27.08 \pm 4.56$ \\
\hline 2.8E-06 & Dong_Hunan & Hmong_Core & CHB.SG & 4.69 & $28.36 \pm 6.05$ \\
\hline $1.0 \mathrm{E}-06$ & Dong_Hunan & Hmong_Core & Tibetan_Core & 4.89 & $29.32 \pm 6.00$ \\
\hline 4.9E-08 & Miao_Sanjiang & Hmong_Core & CDX.SG & 5.46 & $29.33 \pm 5.38$ \\
\hline $1.8 \mathrm{E}-06$ & Dong_Hunan & Hmong_Core & KHV.SG & 4.78 & $29.38 \pm 6.15$ \\
\hline 1.3E-07 & Dong_Hunan & Hmong_Core & CHS.SG & 5.28 & $29.91 \pm 5.67$ \\
\hline 1.3E-07 & Dong_Hunan & Hmong_Core & CHS.SG & 5.28 & $29.91 \pm 5.67$ \\
\hline $7.5 \mathrm{E}-18$ & Miao_Huanjiang & Hmong_Core & Hlai_all & 8.61 & $31.09 \pm 3.61$ \\
\hline 2.3E-12 & Dong_Guizhou & Hmong_Core & KHV.SG & 7.01 & $31.97 \pm 4.56$ \\
\hline 5.7E-19 & Miao_Huanjiang & Hmong_Core & KHV.SG & 8.90 & $32.09 \pm 3.61$ \\
\hline $2.5 E-18$ & Miao_Huanjiang & Hmong_Core & CHB.SG & 8.73 & $33.91 \pm 3.88$ \\
\hline 2.1E-07 & Dong_Guizhou & Hmong_Core & CDX.SG & 5.19 & $34.58 \pm 6.67$ \\
\hline $1.6 \mathrm{E}-18$ & Miao_Huanjiang & Hmong_Core & Zhuang_Guangxi & 8.79 & $35.01 \pm 3.98$ \\
\hline 1.3E-09 & PaThen & Hmong_Core & Zhuang_Guangxi & 6.07 & $37.30 \pm 6.14$ \\
\hline 1.9E-09 & Dong_Guizhou & Hmong_Core & CHB.SG & 6.01 & $38.26 \pm 6.37$ \\
\hline $1.4 \mathrm{E}-15$ & Dong_Guizhou & Hmong_Core & CHS.SG & 7.98 & $38.91 \pm 4.87$ \\
\hline $1.4 \mathrm{E}-15$ & Dong_Guizhou & Hmong_Core & CHS.SG & 7.98 & $38.91 \pm 4.87$ \\
\hline $3.0 \mathrm{E}-10$ & PaThen & Hmong_Core & CHS.SG & 6.30 & $39.73 \pm 6.31$ \\
\hline $3.0 \mathrm{E}-10$ & PaThen & Hmong_Core & CHS.SG & 6.30 & $39.73 \pm 6.31$ \\
\hline 3.8E-09 & PaThen & Hmong_Core & CHB.SG & 5.89 & $40.25 \pm 6.83$ \\
\hline $1.5 \mathrm{E}-09$ & Dong_Guizhou & Hmong_Core & JPT.SG & 6.04 & $40.27 \pm 6.67$ \\
\hline $7.2 \mathrm{E}-19$ & Miao_Huanjiang & Hmong_Core & Tibetan_Core & 8.87 & $40.86 \pm 4.61$ \\
\hline 1.2E-08 & Dong_Guizhou & Hmong_Core & Tibetan_Core & 5.70 & $41.91 \pm 7.09$ \\
\hline 1.7E-05 & Miao_Longsheng & Hmong_Core & KHV.SG & 4.30 & $41.91 \pm 9.74$ \\
\hline 4.1E-05 & Miao_Longsheng & Hmong_Core & CHS.SG & 4.10 & $45.62 \pm 11.13$ \\
\hline 4.1E-05 & Miao_Longsheng & Hmong_Core & CHS.SG & 4.10 & $45.62 \pm 11.13$ \\
\hline 4.6E-05 & Miao_Longsheng & Hmong_Core & CDX.SG & 4.08 & $46.40 \pm 11.38$ \\
\hline
\end{tabular}




\section{Extended Data Table 5.}

\begin{tabular}{|c|c|c|c|c|c|}
\hline \multirow{2}{*}{ Pop } & \multirow{2}{*}{ P-value } & \multicolumn{2}{|c|}{ Ancestry Coefficient } & \multicolumn{2}{|c|}{ Standard Error } \\
\hline & & Mongolia_N & Andaman_HG & Mongolia_N & Andaman_HG \\
\hline Haminmangha_MN & $2.139 \mathrm{E}-01$ & 0.852 & 0.148 & 0.065 & 0.065 \\
\hline Jalainur_EN & $9.769 \mathrm{E}-01$ & 0.992 & 0.008 & 0.072 & 0.072 \\
\hline Xianbei_IA & 4.856E-02 & 0.956 & 0.044 & 0.092 & 0.092 \\
\hline Heishui_Mohe_Medieval & 4.749E-01 & 0.707 & 0.293 & 0.073 & 0.073 \\
\hline Yankovsky_IA & $2.113 \mathrm{E}-01$ & 0.969 & 0.031 & 0.060 & 0.060 \\
\hline Boisman_MN & $5.588 \mathrm{E}-01$ & 0.936 & 0.064 & 0.040 & 0.040 \\
\hline DevilsCave_N & $3.318 \mathrm{E}-01$ & 0.883 & 0.117 & 0.042 & 0.042 \\
\hline U_Xiajiadian_BA_o & 7.984E-02 & 1.046 & -0.046 & 0.065 & 0.065 \\
\hline Yumin_EN & $4.060 \mathrm{E}-02$ & 0.978 & 0.022 & 0.058 & 0.058 \\
\hline Mongolia_N_North & $6.086 \mathrm{E}-02$ & 1.025 & -0.025 & 0.043 & 0.043 \\
\hline Hongshan_MN & $7.480 \mathrm{E}-01$ & 0.869 & 0.131 & 0.044 & 0.044 \\
\hline L_Xiajiadian_LN & $6.424 \mathrm{E}-01$ & 0.837 & 0.163 & 0.045 & 0.045 \\
\hline U_Xiajiadian_BA & 4.833E-01 & 0.900 & 0.100 & 0.057 & 0.057 \\
\hline Jomon_HG & $9.088 \mathrm{E}-01$ & 0.435 & 0.565 & 0.046 & 0.046 \\
\hline Sakhalin_HG & $1.574 \mathrm{E}-01$ & 0.552 & 0.448 & 0.116 & 0.116 \\
\hline Shandong_EN & $3.289 \mathrm{E}-01$ & 0.861 & 0.139 & 0.037 & 0.037 \\
\hline Yangshao_MN & $9.339 \mathrm{E}-01$ & 0.787 & 0.213 & 0.038 & 0.038 \\
\hline Longshan_LN & $6.039 \mathrm{E}-01$ & 0.826 & 0.174 & 0.033 & 0.033 \\
\hline Miaozigou_MN & 8.369E-01 & 0.922 & 0.078 & 0.076 & 0.076 \\
\hline Shimao_LN & $1.909 \mathrm{E}-01$ & 0.853 & 0.147 & 0.047 & 0.047 \\
\hline Henan_LBIA & $3.191 \mathrm{E}-01$ & 0.797 & 0.203 & 0.034 & 0.034 \\
\hline Omnogovi_WestHan_IA & $5.448 \mathrm{E}-01$ & 0.786 & 0.214 & 0.042 & 0.042 \\
\hline Qijia_LN & $4.798 \mathrm{E}-01$ & 0.780 & 0.220 & 0.038 & 0.038 \\
\hline Dacaozi_IA & $2.658 \mathrm{E}-01$ & 0.820 & 0.180 & 0.044 & 0.044 \\
\hline Nepal_LN_BA_IA & $9.297 \mathrm{E}-02$ & 0.702 & 0.298 & 0.038 & 0.038 \\
\hline Laos_N & $6.922 \mathrm{E}-01$ & 0.442 & 0.558 & 0.050 & 0.050 \\
\hline Malaysia_LN.SG & $3.746 \mathrm{E}-01$ & 0.483 & 0.517 & 0.050 & 0.050 \\
\hline Vietnam_N & 8.132E-01 & 0.426 & 0.574 & 0.105 & 0.105 \\
\hline Vietnam_LN_BA & 3.047E-01 & 0.481 & 0.519 & 0.115 & 0.115 \\
\hline Vietnam_BA & $6.560 \mathrm{E}-01$ & 0.663 & 0.337 & 0.050 & 0.050 \\
\hline Thailand_IA & $3.194 \mathrm{E}-01$ & 0.635 & 0.365 & 0.065 & 0.065 \\
\hline Qihe_EN & $5.139 \mathrm{E}-01$ & 0.583 & 0.417 & 0.058 & 0.058 \\
\hline Liangdao1_EN & $7.219 \mathrm{E}-01$ & 0.527 & 0.473 & 0.059 & 0.059 \\
\hline Liangdao2_EN & $3.856 \mathrm{E}-01$ & 0.570 & 0.430 & 0.056 & 0.056 \\
\hline Fujian_LN & $1.814 \mathrm{E}-02$ & 0.608 & 0.392 & 0.047 & 0.047 \\
\hline Hanben_IA & $8.145 \mathrm{E}-01$ & 0.688 & 0.312 & 0.031 & 0.031 \\
\hline Gongguan_IA & $5.574 \mathrm{E}-01$ & 0.672 & 0.328 & 0.061 & 0.061 \\
\hline
\end{tabular}




\begin{tabular}{|c|c|c|c|c|c|}
\hline Vanuatu_2900BP_all & $5.854 \mathrm{E}-01$ & 0.638 & 0.362 & 0.061 & 0.061 \\
\hline Daur & $5.628 \mathrm{E}-01$ & 0.883 & 0.117 & 0.032 & 0.032 \\
\hline Xibo & 2.916E-02 & 0.840 & 0.160 & 0.034 & 0.034 \\
\hline Hezhen & $1.081 \mathrm{E}-01$ & 0.905 & 0.095 & 0.033 & 0.033 \\
\hline Nanai & $2.966 \mathrm{E}-01$ & 0.966 & 0.034 & 0.034 & 0.034 \\
\hline Negidal & $1.523 \mathrm{E}-01$ & 1.017 & -0.017 & 0.041 & 0.041 \\
\hline Nivh & $1.268 \mathrm{E}-01$ & 0.979 & 0.021 & 0.036 & 0.036 \\
\hline Oroqen & $9.378 \mathrm{E}-02$ & 0.936 & 0.064 & 0.034 & 0.034 \\
\hline Ulchi & 7.103E-02 & 0.990 & 0.010 & 0.034 & 0.034 \\
\hline Korean & 4.766E-01 & 0.822 & 0.178 & 0.032 & 0.032 \\
\hline Japanese & $1.255 \mathrm{E}-01$ & 0.787 & 0.213 & 0.029 & 0.029 \\
\hline JPT.SG & $9.384 \mathrm{E}-02$ & 0.795 & 0.205 & 0.030 & 0.030 \\
\hline CHB.SG & $1.701 \mathrm{E}-01$ & 0.789 & 0.211 & 0.030 & 0.030 \\
\hline CHS.SG & $3.262 \mathrm{E}-01$ & 0.746 & 0.254 & 0.029 & 0.029 \\
\hline Han_NChina & $3.269 \mathrm{E}-01$ & 0.782 & 0.218 & 0.030 & 0.030 \\
\hline Han_Shanxi & $7.612 \mathrm{E}-01$ & 0.780 & 0.220 & 0.030 & 0.030 \\
\hline Han_Shandong & $3.585 \mathrm{E}-01$ & 0.777 & 0.223 & 0.030 & 0.030 \\
\hline Han_Henan & $3.620 \mathrm{E}-01$ & 0.797 & 0.203 & 0.034 & 0.034 \\
\hline Han_Jiangsu & $6.479 \mathrm{E}-01$ & 0.790 & 0.210 & 0.031 & 0.031 \\
\hline Han_Shanghai & $3.596 \mathrm{E}-01$ & 0.771 & 0.229 & 0.035 & 0.035 \\
\hline Han_Hubei & $3.524 \mathrm{E}-01$ & 0.751 & 0.249 & 0.033 & 0.033 \\
\hline Tujia & $2.355 \mathrm{E}-01$ & 0.761 & 0.239 & 0.030 & 0.030 \\
\hline Han_Chongqing & 3.799E-01 & 0.755 & 0.245 & 0.035 & 0.035 \\
\hline Han_Sichuan & 3.907E-01 & 0.747 & 0.253 & 0.030 & 0.030 \\
\hline Han_Zhejiang & 2.320E-01 & 0.757 & 0.243 & 0.032 & 0.032 \\
\hline Han_Fujian & $3.615 \mathrm{E}-01$ & 0.724 & 0.276 & 0.032 & 0.032 \\
\hline Han_Taiwan & $6.705 \mathrm{E}-01$ & 0.742 & 0.258 & 0.031 & 0.031 \\
\hline Han_Hakka & $4.255 \mathrm{E}-01$ & 0.735 & 0.265 & 0.030 & 0.030 \\
\hline Han_Yunnan & $3.207 \mathrm{E}-01$ & 0.749 & 0.251 & 0.029 & 0.029 \\
\hline Han_Guangdong & 3.999E-01 & 0.712 & 0.288 & 0.031 & 0.031 \\
\hline Han_Guangxi & 4.243E-01 & 0.704 & 0.296 & 0.029 & 0.029 \\
\hline Han_Haikou & 4.678E-01 & 0.721 & 0.279 & 0.028 & 0.028 \\
\hline Monguor & 4.567E-02 & 0.770 & 0.230 & 0.031 & 0.031 \\
\hline Yugur & $1.634 \mathrm{E}-01$ & 0.772 & 0.228 & 0.030 & 0.030 \\
\hline Qiang_Daofu & $1.641 \mathrm{E}-01$ & 0.760 & 0.240 & 0.030 & 0.030 \\
\hline Qiang_Danba & $1.713 \mathrm{E}-01$ & 0.782 & 0.218 & 0.030 & 0.030 \\
\hline Tibetan_Xinlong & $2.645 \mathrm{E}-01$ & 0.759 & 0.241 & 0.031 & 0.031 \\
\hline Tibetan_Gangcha & 1.053E-01 & 0.774 & 0.226 & 0.030 & 0.030 \\
\hline Tibetan_Xunhua & 3.318E-02 & 0.723 & 0.277 & 0.034 & 0.034 \\
\hline Tibetan_Chamdo & 2.783E-01 & 0.770 & 0.230 & 0.030 & 0.030 \\
\hline Tibetan_Lhasa & 3.319E-01 & 0.754 & 0.246 & 0.031 & 0.031 \\
\hline Tibetan_Nagqu & $5.123 \mathrm{E}-01$ & 0.759 & 0.241 & 0.030 & 0.030 \\
\hline Tibetan_Shigatse & $3.908 \mathrm{E}-01$ & 0.724 & 0.276 & 0.031 & 0.031 \\
\hline Tibetan_Shannan & 3.233E-01 & 0.722 & 0.278 & 0.031 & 0.031 \\
\hline
\end{tabular}




\begin{tabular}{|c|c|c|c|c|c|}
\hline Sherpa.DG & $2.050 \mathrm{E}-02$ & 0.713 & 0.287 & 0.039 & 0.039 \\
\hline Naxi & 3.315E-01 & 0.728 & 0.272 & 0.030 & 0.030 \\
\hline Yi & 5.347E-01 & 0.756 & 0.244 & 0.030 & 0.030 \\
\hline Lahu_China & 7.062E-01 & 0.652 & 0.348 & 0.029 & 0.029 \\
\hline Lahu_Vietnam & $7.231 \mathrm{E}-01$ & 0.682 & 0.318 & 0.030 & 0.030 \\
\hline Cong & $6.635 \mathrm{E}-01$ & 0.634 & 0.366 & 0.030 & 0.030 \\
\hline HaNhi & $3.238 \mathrm{E}-01$ & 0.695 & 0.305 & 0.029 & 0.029 \\
\hline Sila & $5.416 \mathrm{E}-01$ & 0.696 & 0.304 & 0.031 & 0.031 \\
\hline She & $3.514 \mathrm{E}-01$ & 0.730 & 0.270 & 0.031 & 0.031 \\
\hline Miao_Hunan & $4.511 \mathrm{E}-01$ & 0.727 & 0.273 & 0.030 & 0.030 \\
\hline Miao_Longlin & 6.374E-01 & 0.687 & 0.313 & 0.033 & 0.033 \\
\hline Miao_Xilin & 3.733E-01 & 0.681 & 0.319 & 0.033 & 0.033 \\
\hline Miao_Rongshui & $1.874 \mathrm{E}-01$ & 0.703 & 0.297 & 0.032 & 0.032 \\
\hline Miao_Sanjiang & 2.764E-01 & 0.681 & 0.319 & 0.033 & 0.033 \\
\hline Miao_Huanjiang & 5.102E-01 & 0.703 & 0.297 & 0.031 & 0.031 \\
\hline Miao_Longsheng & $7.503 \mathrm{E}-01$ & 0.699 & 0.301 & 0.031 & 0.031 \\
\hline Miao_Ziyuan & $1.504 \mathrm{E}-01$ & 0.709 & 0.291 & 0.032 & 0.032 \\
\hline Hmong & $3.666 \mathrm{E}-01$ & 0.692 & 0.308 & 0.031 & 0.031 \\
\hline PaThen & 4.965E-02 & 0.729 & 0.271 & 0.032 & 0.032 \\
\hline Dao & $3.200 \mathrm{E}-01$ & 0.689 & 0.311 & 0.031 & 0.031 \\
\hline Gelao & $2.265 \mathrm{E}-01$ & 0.673 & 0.327 & 0.030 & 0.030 \\
\hline LaChi & $3.818 \mathrm{E}-01$ & 0.666 & 0.334 & 0.033 & 0.033 \\
\hline Colao & $3.944 \mathrm{E}-01$ & 0.695 & 0.305 & 0.032 & 0.032 \\
\hline Maonan & 3.220E-01 & 0.676 & 0.324 & 0.031 & 0.031 \\
\hline Mulam & $1.359 \mathrm{E}-01$ & 0.691 & 0.309 & 0.031 & 0.031 \\
\hline Dong_Guizhou & 4.464E-01 & 0.704 & 0.296 & 0.031 & 0.031 \\
\hline Dong_Hunan & $3.626 \mathrm{E}-01$ & 0.700 & 0.300 & 0.031 & 0.031 \\
\hline Hlai_Qiongzhong & 5.390E-01 & 0.656 & 0.344 & 0.029 & 0.029 \\
\hline Hlai_HO & 2.707E-01 & 0.651 & 0.349 & 0.034 & 0.034 \\
\hline Zhuang_HO & $4.818 \mathrm{E}-01$ & 0.688 & 0.312 & 0.029 & 0.029 \\
\hline Zhuang_Guangxi & 4.656E-01 & 0.689 & 0.311 & 0.028 & 0.028 \\
\hline Zhuang_Yunnan & 2.399E-01 & 0.681 & 0.319 & 0.030 & 0.030 \\
\hline Nung & 4.955E-01 & 0.680 & 0.320 & 0.029 & 0.029 \\
\hline Tay & 3.502E-01 & 0.680 & 0.320 & 0.030 & 0.030 \\
\hline BoY & $9.470 \mathrm{E}-02$ & 0.685 & 0.315 & 0.033 & 0.033 \\
\hline Dai & 2.867E-01 & 0.670 & 0.330 & 0.031 & 0.031 \\
\hline CDX.SG & 4.419E-01 & 0.663 & 0.337 & 0.029 & 0.029 \\
\hline Muong & $6.631 \mathrm{E}-01$ & 0.671 & 0.329 & 0.030 & 0.030 \\
\hline Kinh & 7.350E-01 & 0.663 & 0.337 & 0.030 & 0.030 \\
\hline Vietnamese & $3.438 \mathrm{E}-01$ & 0.678 & 0.322 & 0.030 & 0.030 \\
\hline KHV.SG & 5.111E-01 & 0.664 & 0.336 & 0.028 & 0.028 \\
\hline Dusun & 3.060E-01 & 0.586 & 0.414 & 0.031 & 0.031 \\
\hline Murut & 5.699E-01 & 0.597 & 0.403 & 0.032 & 0.032 \\
\hline Malay & $2.518 \mathrm{E}-01$ & 0.482 & 0.518 & 0.031 & 0.031 \\
\hline
\end{tabular}


bioRxiv preprint doi: https://doi.org/10.1101/2020.11.08.373225; this version posted November 8, 2020. The copyright holder for this preprint (which was not certified by peer review) is the author/funder, who has granted bioRxiv a license to display the preprint in perpetuity. It is made available under aCC-BY-NC 4.0 International license.

\begin{tabular}{|c|c|c|c|c|c|}
\hline Lao & 8.070E-01 & 0.592 & 0.408 & 0.030 & 0.030 \\
\hline Thai & 4.131E-02 & 0.538 & 0.462 & 0.032 & 0.032 \\
\hline Cambodian & 1.697E-01 & 0.515 & 0.485 & 0.031 & 0.031 \\
\hline Mang & 6.467E-01 & 0.615 & 0.385 & 0.030 & 0.030 \\
\hline Htin_Mal & $6.216 \mathrm{E}-01$ & 0.545 & 0.455 & 0.033 & 0.033 \\
\hline Mlabri & 5.319E-01 & 0.498 & 0.502 & 0.039 & 0.039 \\
\hline Ami & $5.141 \mathrm{E}-01$ & 0.642 & 0.358 & 0.032 & 0.032 \\
\hline Atayal & $6.564 \mathrm{E}-01$ & 0.676 & 0.324 & 0.034 & 0.034 \\
\hline Kankanaey & 7.745E-01 & 0.668 & 0.332 & 0.032 & 0.032 \\
\hline Tagalog & 5.997E-01 & 0.592 & 0.408 & 0.031 & 0.031 \\
\hline Malaysia_Jehai.SG & 9.572E-01 & 0.177 & 0.823 & 0.049 & 0.049 \\
\hline Onge.DG & 7.643E-01 & -0.036 & 1.036 & 0.046 & 0.046 \\
\hline
\end{tabular}



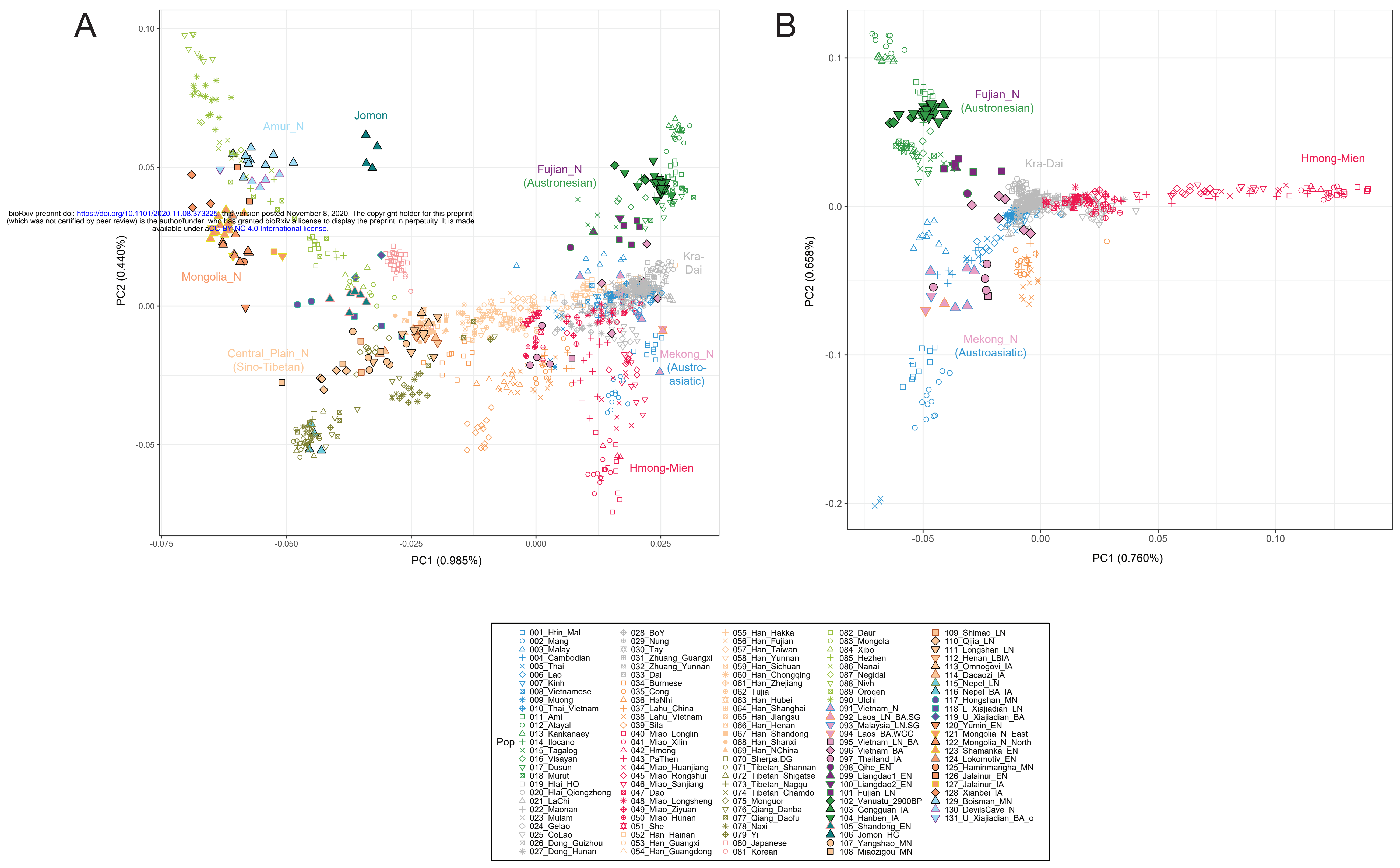


\section{C}
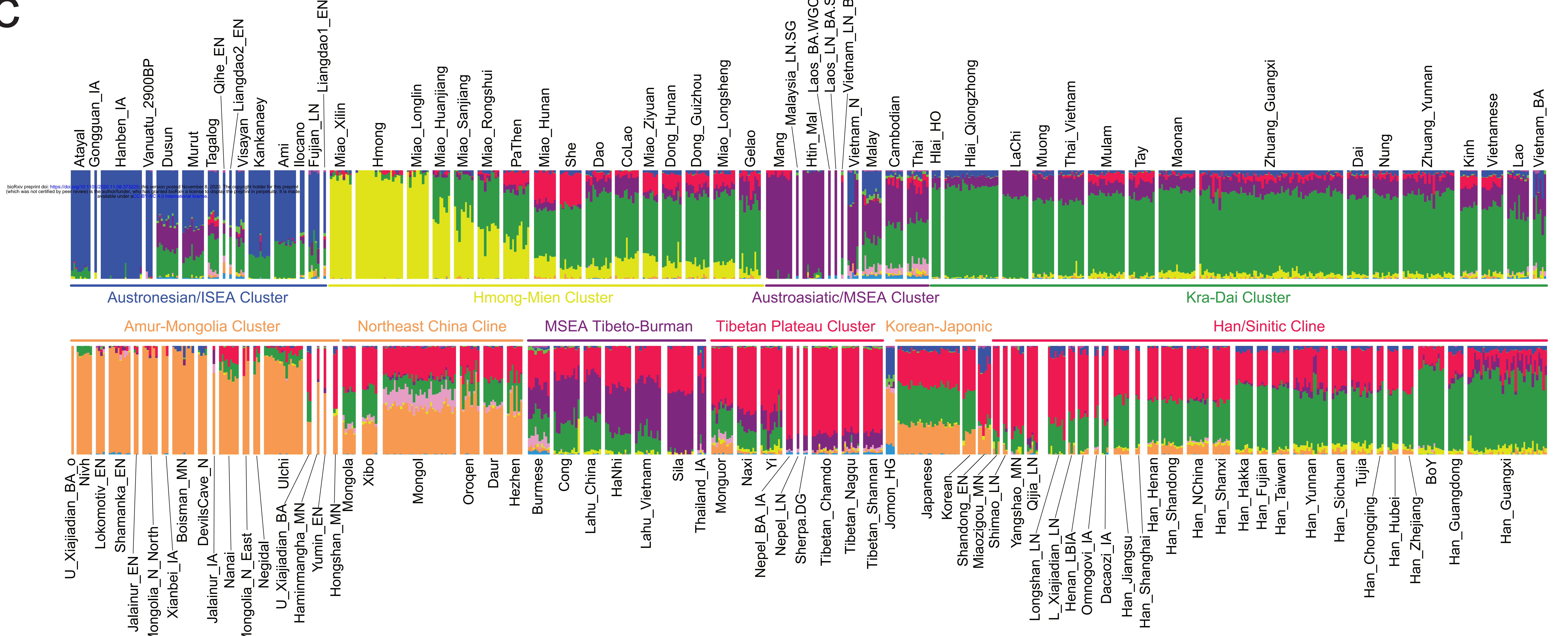


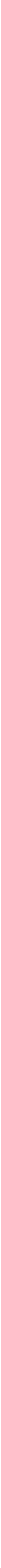




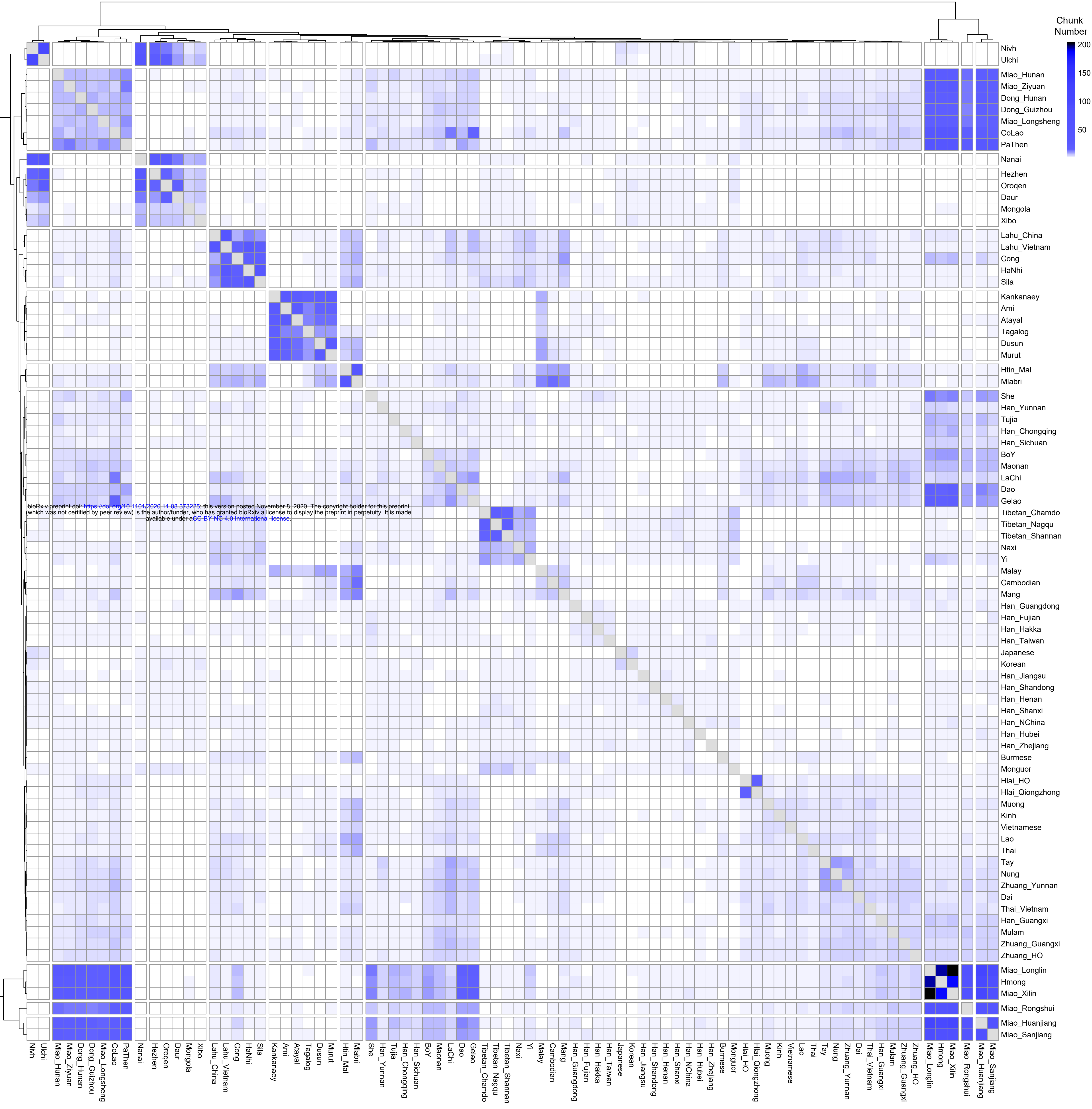




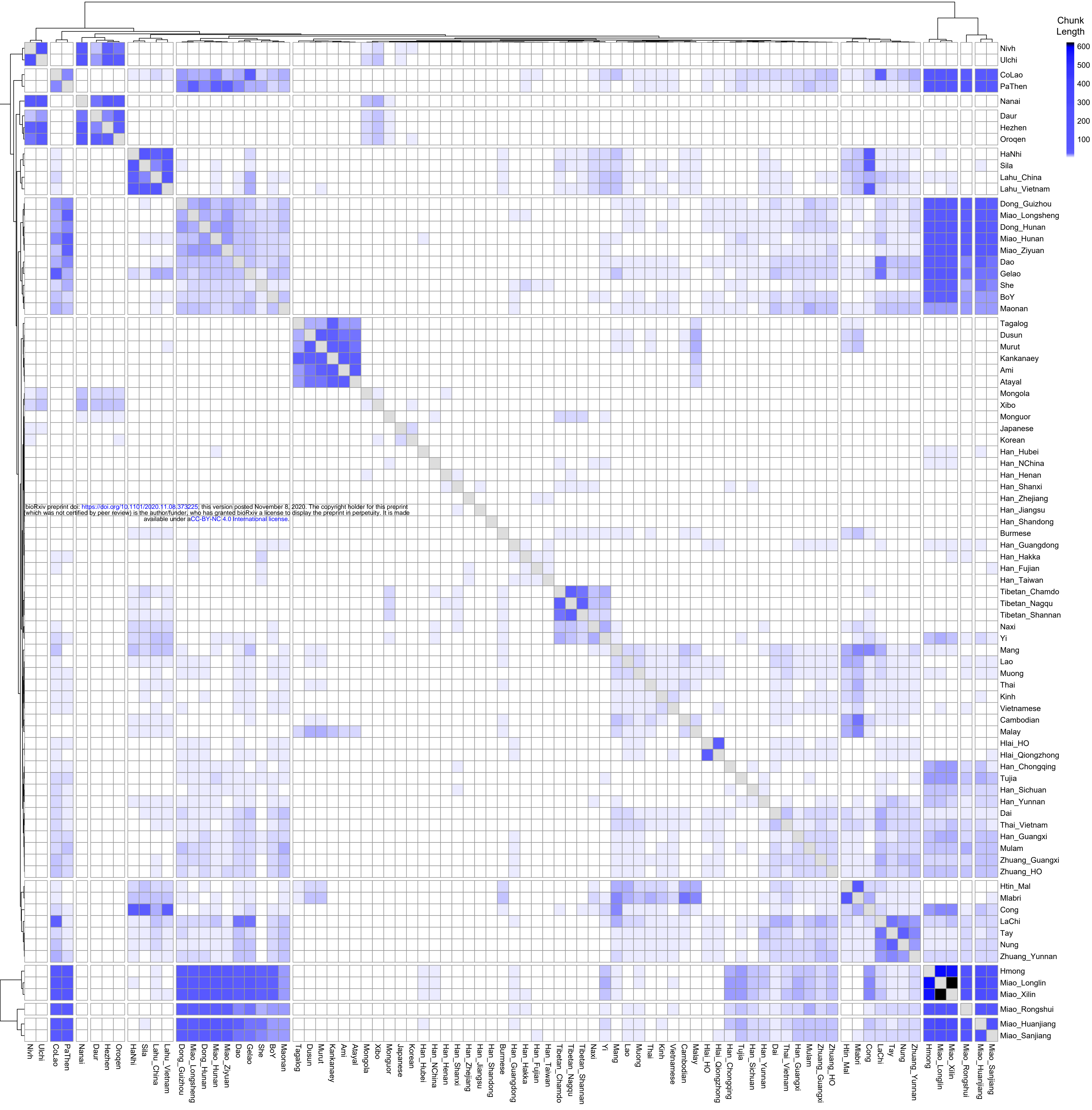


bioRxiv preprint doi: https://doi.org/10.1101/2020.11.08.373225; this version posted November 8, 2020. Th (which was not certified by peer review) is the author/funder, who has granted bioRxiv a license to display th

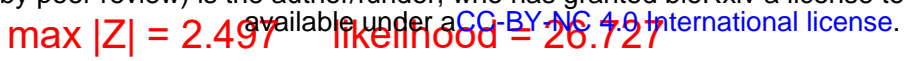

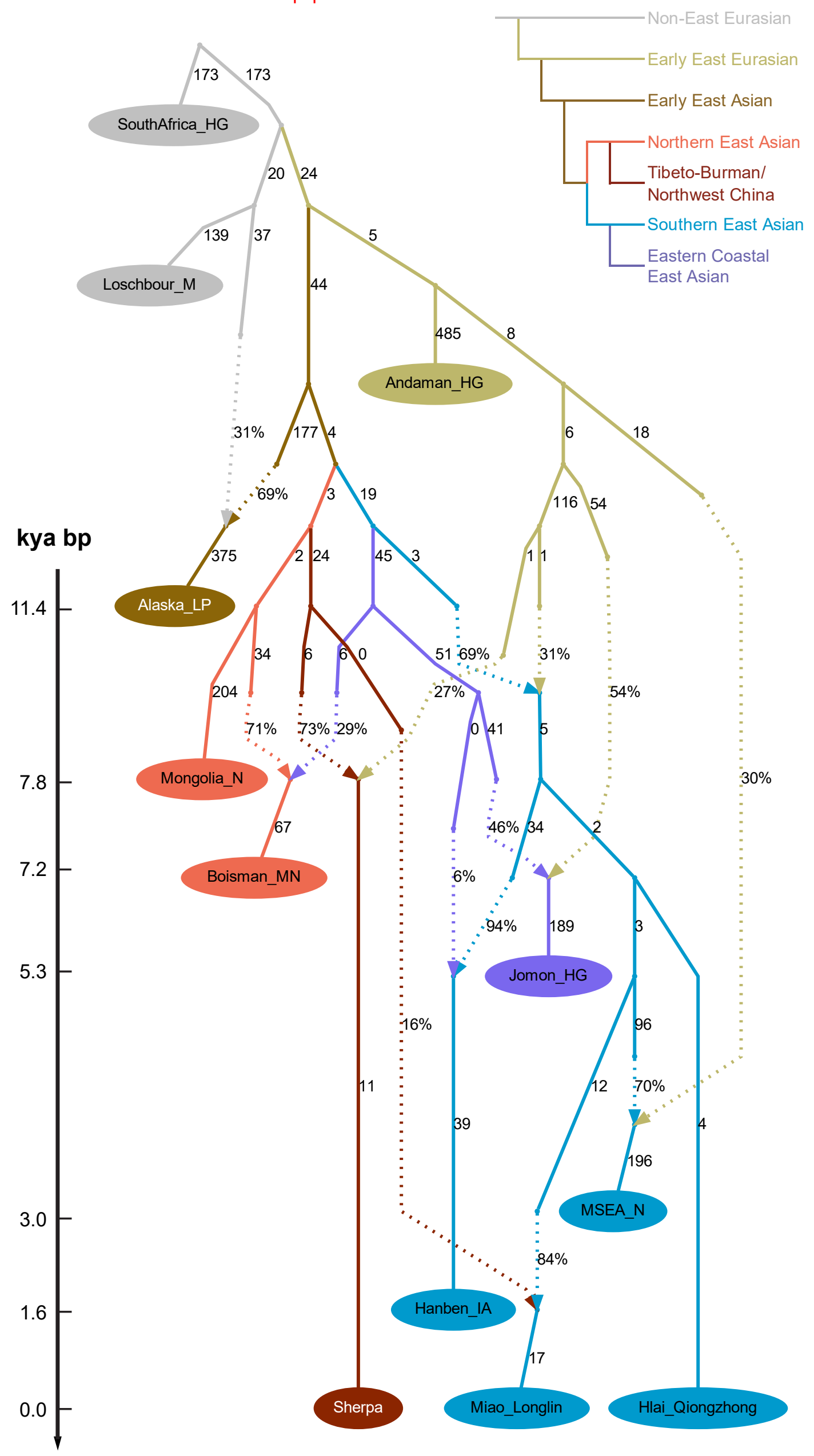




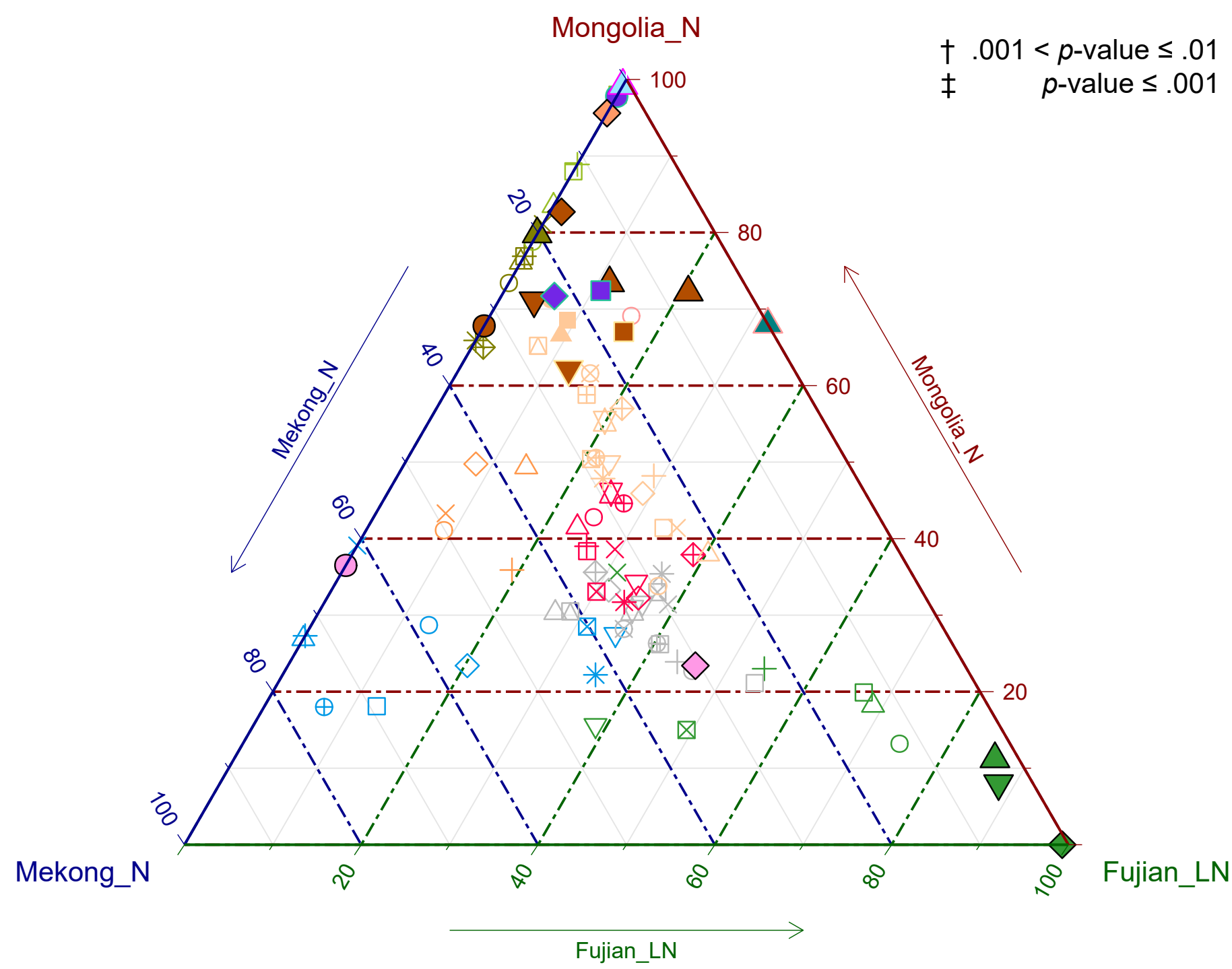
$\oplus$ 000_Mlabri
- 020_Maonan $\ddagger$
+ 040_PaThen
021 Mulam†
$\times$ 041_Miao_Huanjiang
060_Han_Hubei
$\bigcirc$ 080_Vietnam_BA
001_Htin_Mal
022_Gelao†
$\diamond$ 042_Miao_Rongshui
$\triangle$ 003_Malay
+004 Cambodian
023 CoLao
$\nabla$ 043_Miao_Sanjiang
024 Dong Guizhout $\otimes 044$ Daot
005_Thai†
* 045_Miao_Longsheng
$\diamond$ 006_Lao
$\checkmark 007$ Kinh
$\triangle 008$ Vietnamese
026_BoY
$\diamond$ 046_Miao_Ziyuan†
$\oplus$ 047_Miao_Hunan
027_Nung
\& 048 She
* 009_Muong
010_Ami
011_Atayal
029_Zhuang_Guangxi†
030_Zhuang_Yunnant
049_Han_Hainan
061_Han_Shanghai
062_Han_Jiangsu
064 Han Shandong
065 Han Shanxi
031 Dai
$\triangle$ 012_Kankanaey
032
050_Han_Guangxi†
066_Han_NChina
067_Sherpa.DG
081 Thailand IA
+ 013_llocano
051 Han Guangdong
068 Tibetan Shannan
069_Tibetan_Shigatse
070_Tibetan_Nagqu
052 Han Hakka
033_HaNhi
$\times 015$
034 Lahu China
035 Lahu Vietnam
053_Han_Fujian
054 Han Taiwan
071 Tibetan Chamdo
* 072_Naxi
055 Han Yunnan
073_Yi
074 Korean
036_Sila
$\otimes$ 016_Murut
056_Han_Sichuan
057_Han_Chongqing
075 Daur
076_Mongola
017_Hlai_HO
$\square$ 037_Miao_Longlin
018 Hlai Qiongzhongt○ 038 Miao Xilin
058_Han_Zhejiang
077_Xibo
082 Vanuatu_2900BP
$\triangle$ 083_Gongguan_IA
084 Hanben IA
019_LaChi
$\triangle$ 039_Hmong
059_Tujia
078_Hezhen
085_Shandong_EN
O 086_Yangshao_MN
087 Shimao $L \bar{N}$
088 Qijia LN
$\checkmark$ 089_Longshan_LN
-090_Henan_LBIA
091 Omnogovi IA
$\triangle 092$ Dacaozi_IA
$\triangle$ 093_Nepel_LNIA†
094 Hongshan MN
- 095 L Xiajiadian LN
096_U_Xiajiadian_BA
097_Xianbei_IA
098 DevilsCave N 


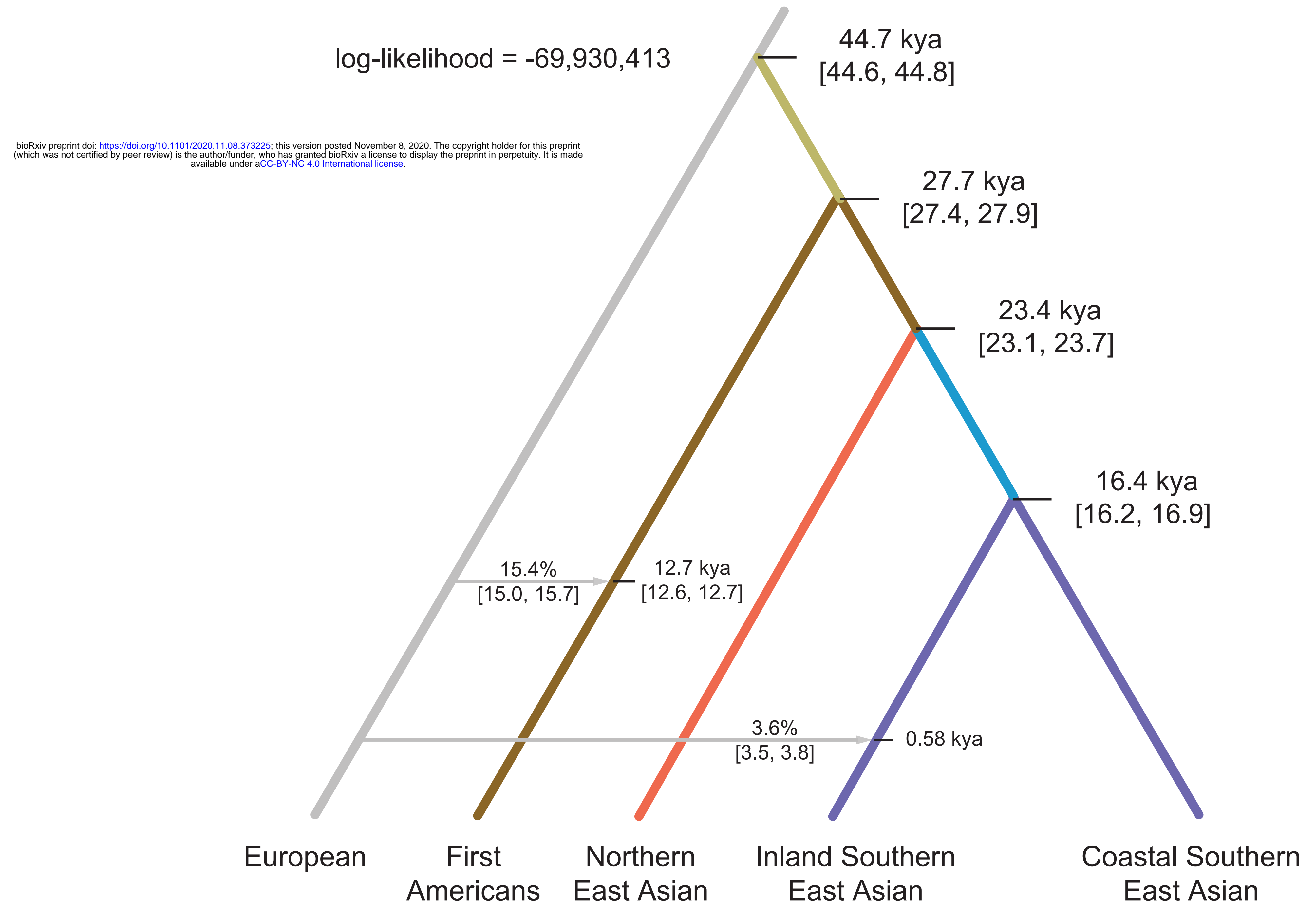




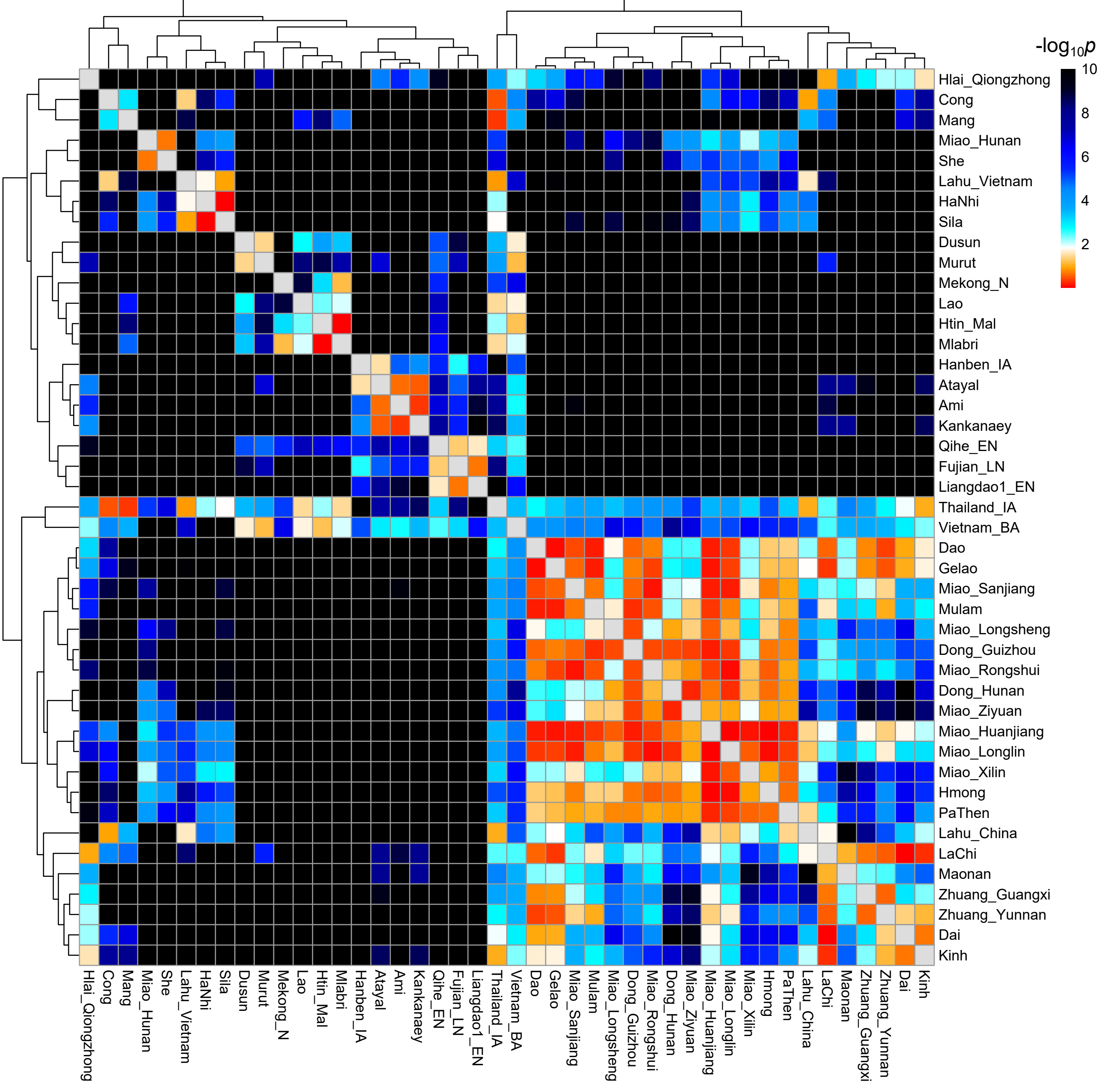




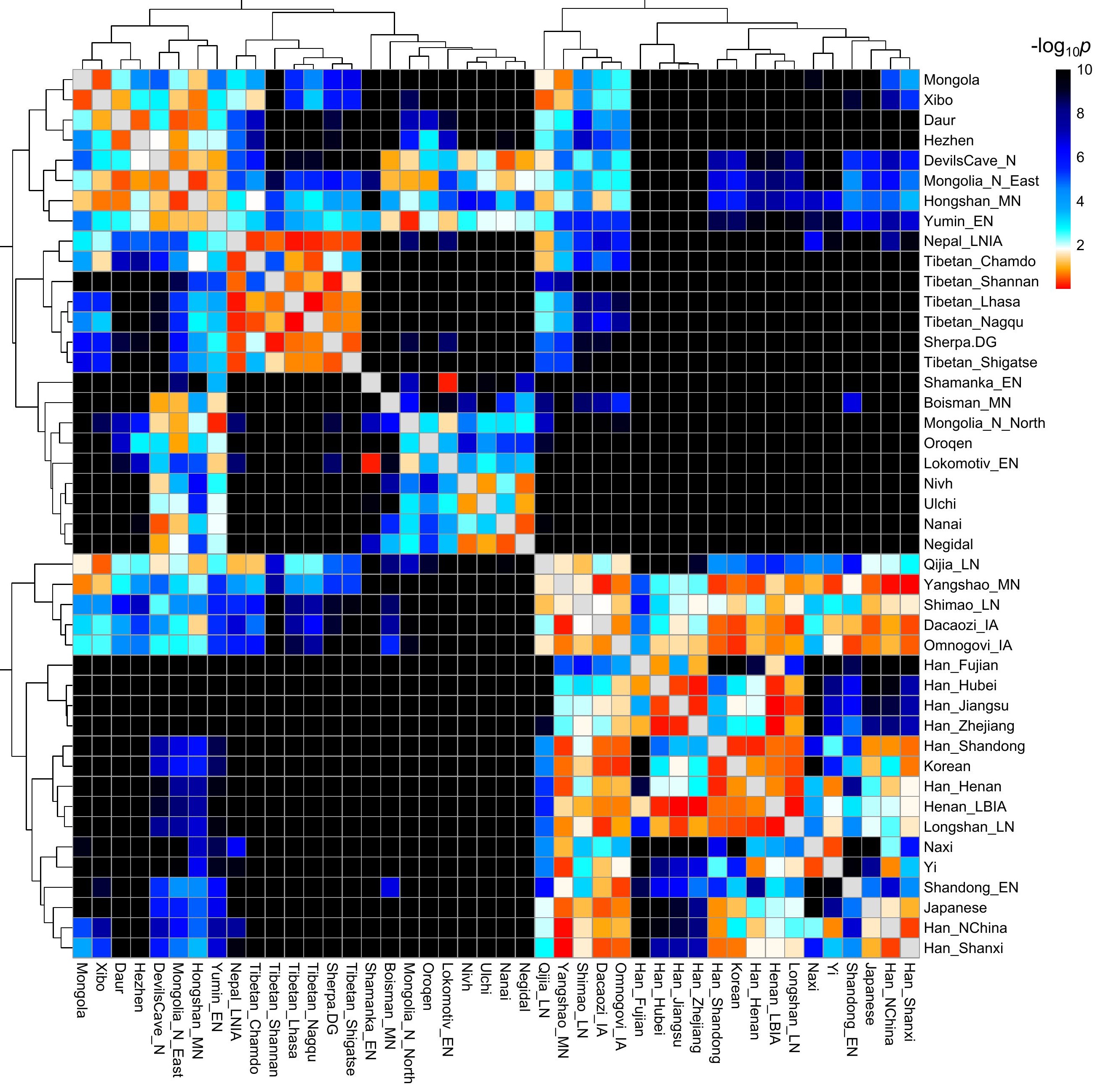





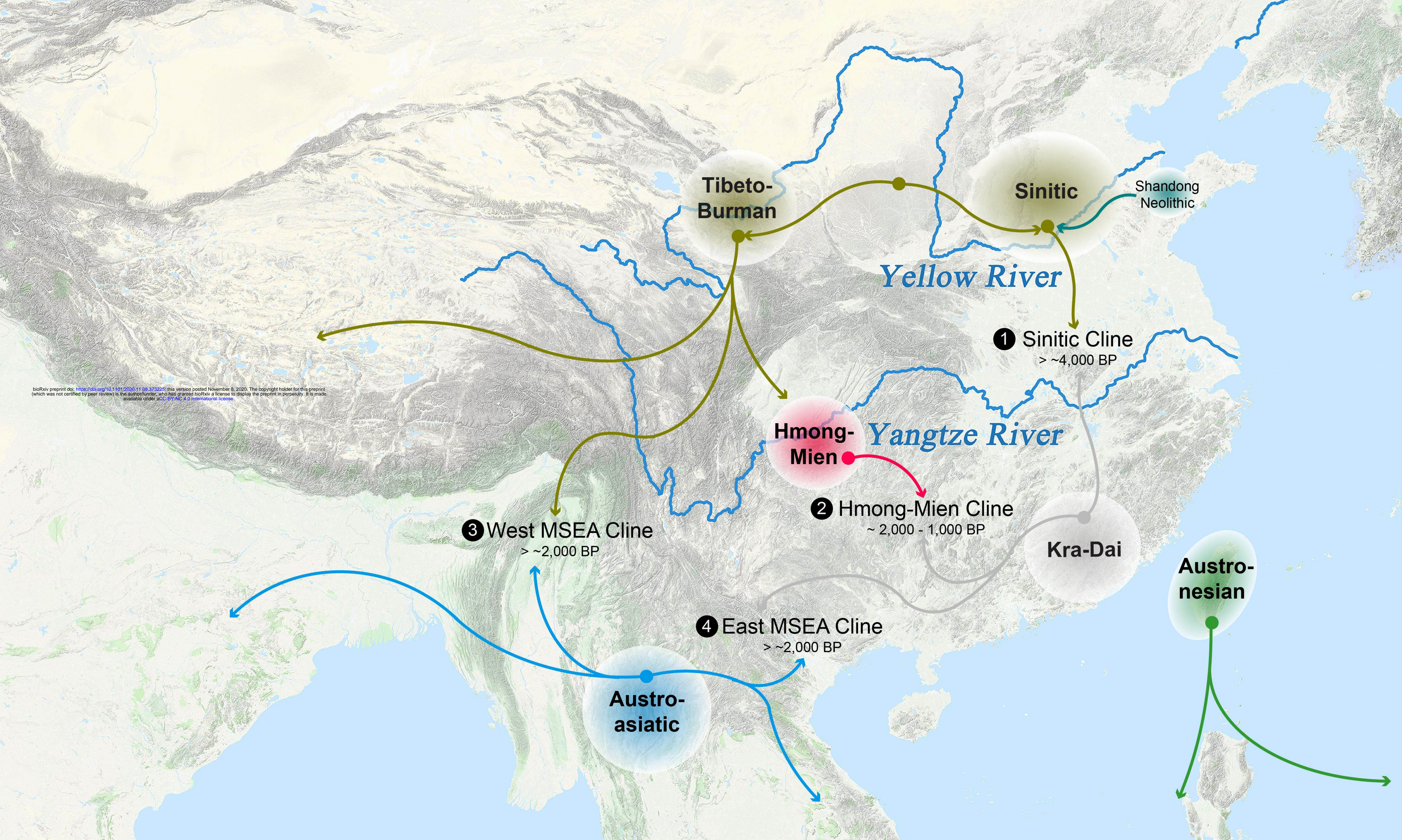

